\title{
The Effect of Reputation Shocks to Rating Agencies on Corporate Disclosures
}

\author{
by \\ Subramanian Sethuraman \\ Business Administration \\ Duke University
}

Date:

Approved:

Mohan Venkatachalam, Supervisor

Shane Dikolli

John Graham

William Mayew

Rahul Vashishtha

Dissertation submitted in partial fulfillment of the requirements for the degree of

Doctor of Philosophy in Business Administration in the Graduate School of Duke University 


\title{
$\underline{\text { ABSTRACT }}$ \\ The Effect of Reputation Shocks to Rating Agencies on Corporate Disclosures
}

\author{
by \\ Subramanian Sethuraman \\ Business Administration \\ Duke University
}

Date:

Approved:

Mohan Venkatachalam, Supervisor

Shane Dikolli

John Graham

William Mayew

Rahul Vashishtha

An abstract of a dissertation submitted in partial fulfillment of the requirements for the degree of Doctor of Philosophy in Business Administration in the Graduate School of Duke University 
Copyright (C) 2016 by Subramanian Sethuraman All rights reserved except the rights granted by the Creative Commons Attribution-Noncommercial License 


\begin{abstract}
This paper explores the effect of credit rating agency's (CRA) reputation on the discretionary disclosures of corporate bond issuers. Academics, practitioners, and regulators disagree on the informational role played by major CRAs and the usefulness of credit ratings in influencing investors' perception of the credit risk of bond issuers. Using management earnings forecasts as a measure of discretionary disclosure, I find that investors demand more (less) disclosure from corporate bond issuers when the ratings become less (more) credible. In addition, using content analytics, I find that bond issuers disclose more qualitative (i.e. textual) information during periods of low CRA reputation to aid investors better assess credit risk. That the corporate managers alter their voluntary disclosure in response to CRA reputation shocks is consistent with credit ratings providing incremental information to investors and reducing adverse selection in lending markets. Overall, consistent with theoretical predictions in prior literature, my findings suggest that managers rely on voluntary disclosure as a credible mechanism to reduce information asymmetry in bond markets.
\end{abstract}


I dedicate this work to my wife, Archana; to my parents, Sethuraman and Jayalakshmi; and to my brothers, Rajan and Krishna. Their support and encouragement have been invaluable. 


\section{Contents}

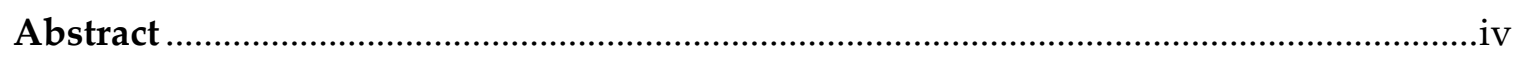

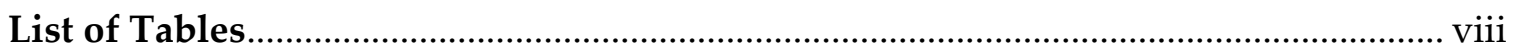

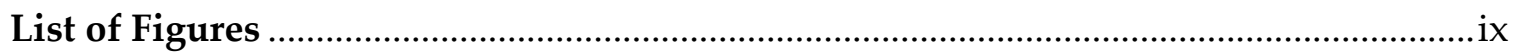

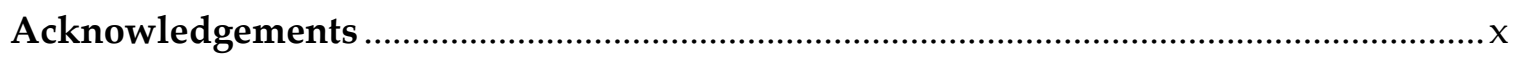

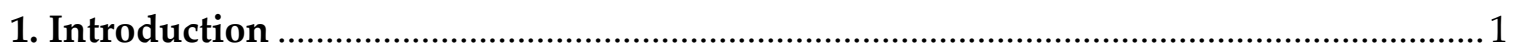

2. Prior Literature and Hypothesis Development ...........................................................

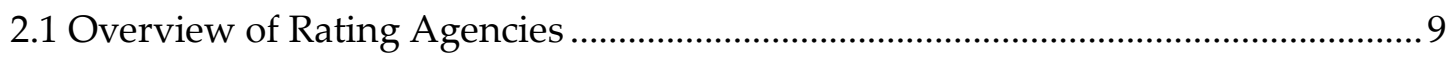

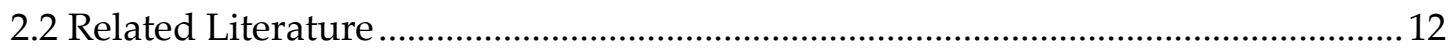

2.2.1 Information Content in Credit Ratings ........................................................... 12

2.2.2 Management Forecasts ................................................................................ 13

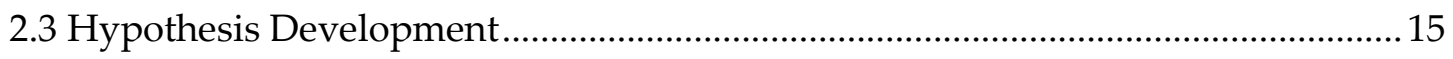

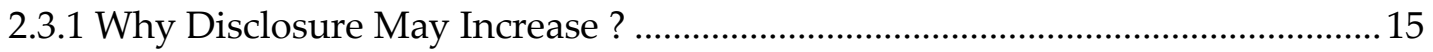

2.3.2 Why Disclosure May Not Change ?................................................................. 17

3. Research Design and Sample Selection ............................................................... 19

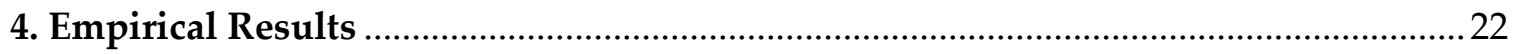

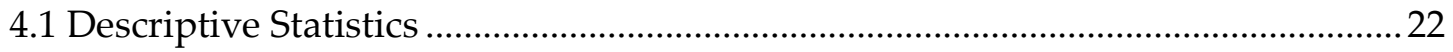

4.2 Empirical Validation of Reputation Shocks......................................................... 23

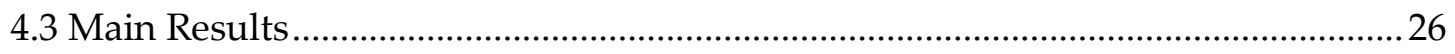

4.4 Cross-Sectional Variations in Disclosure Changes ................................................ 27

4.4.1 Partition Based on Rating Changes in Time-series ...........................................27

4.4.2 Partition Based on Credit Ratings ................................................................ 28 
4.4.3 S\&P versus Egan Jones Ratings ...................................................................... 30

4.4.4 Partition Based on R\&D Expenses ................................................................. 30

4.4.5 Partition Based on Immediate Financing Needs.................................................... 32

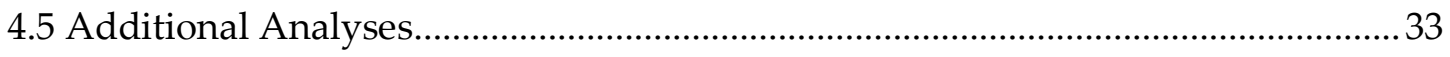

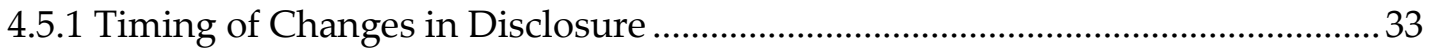

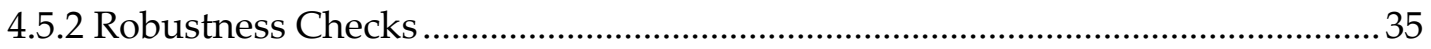

4.5.3 Confounding Effects due to Arthur Andersen Audit Clients .............................37

4.6 Content Analytics and Alternate Outcome Variables ..............................................38

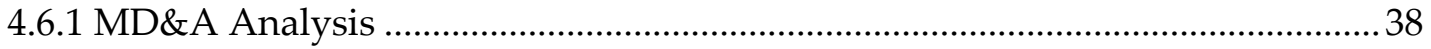

4.6.2 Qualitative Information in Management Forecasts.......................................... 41

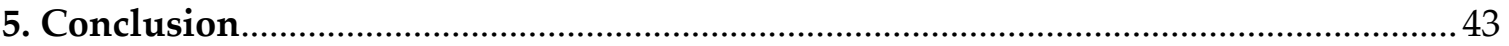

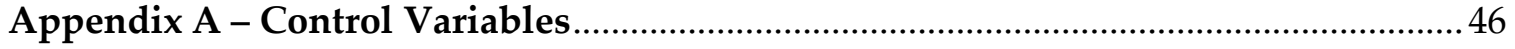

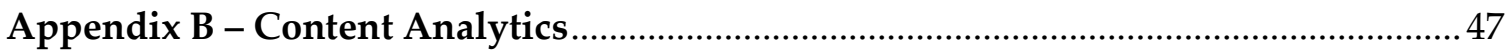

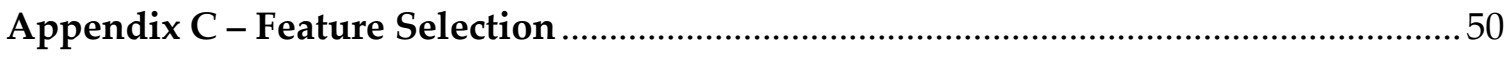

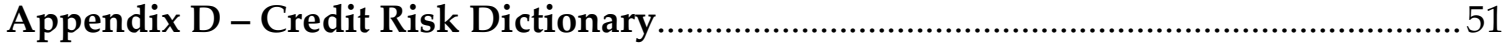

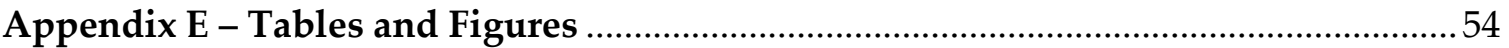

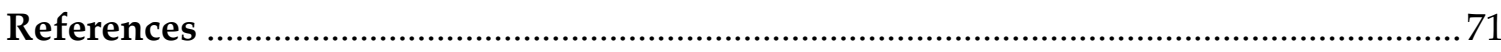

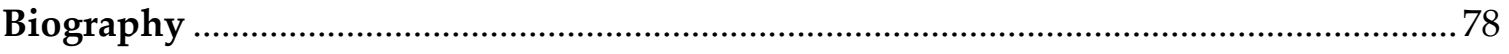




\section{List of Tables}

Table 1 Descriptive Statistics and Correlation Matrix …....................................................56

Table 2 Investor Response to Reputation Shocks .............................................................59

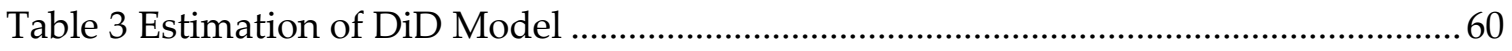

Table 4 Partition Based on Rating Changes in Time Series.................................................61

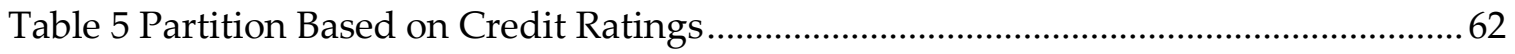

Table 6 Partition Based on Egan-Jones Rating .................................................................63

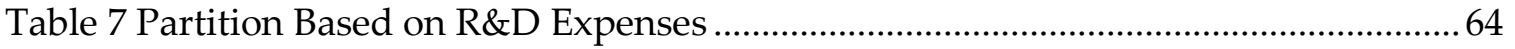

Table 8 Partition Based on Immediate Financing Needs..................................................... 65

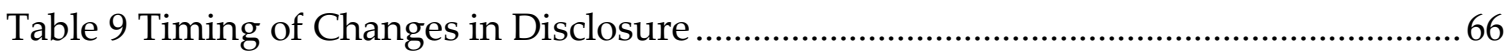

Table 10 Nearest Neighbor Matching and Entropy Balancing ..........................................67

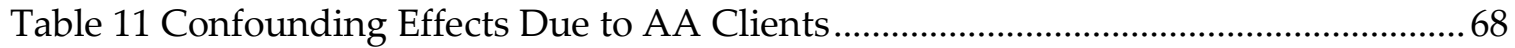

Table 12 Estimation of DiD Model for MD\&A Outcome Variables....................................69

Table 13 Estimation of DiD Model using Qualitative Information in Forecasts................70 


\section{List of Figures}

Figure 1 Timeline of Key Events and Sample Periods ......................................................55 


\section{Acknowledgements}

I am deeply indebted to my dissertation chair, Mohan Venkatachalam, for his guidance throughout my Ph.D. program at Duke University. I would like to express my heartfelt gratitude to Bill Mayew, for guiding me through several research projects and for being a source of inspiration to me. I am grateful for the invaluable guidance and support I received from my dissertation committee members: Shane Dikolli, John Graham, and Rahul Vashishtha. I thank Mary Ellen Carter, Qi Chen, Scott Dyreng, Frank Ecker, Xu Jiang, Per Olsson, Katherine Schipper, Thomas Steffen, Vish Viswanathan, and my fellow PhD students at Duke University for their helpful comments and suggestions. I am also grateful for comments received during seminar presentations at Boston College, Cornell University, Dartmouth College, Harvard Business School, Indiana University, Texas A\&M University at College Station, University of Colorado at Boulder, University of Pennsylvania, University of Southern California, University of Texas at Austin, and Yale University. I thank Peter Arnold (Regional Director, Egan-Jones Rating Company) for providing me with Egan-Jones Rating data for use in my research. I also thank Professor Douglas Breeden and researchers at Amundi Smith Breeden LLC for sharing their insights on US bond market. I am grateful for financial support provided by Duke University and the Deloitte Foundation. Any remaining errors are my own. 


\section{Introduction}

Reputation plays a key role in mitigating adverse selection problems (Mailath and Samuelson, 2001, 2015). A shock to a firm's reputation affects the uncertainty that stakeholders face in transacting with the firm (Klein and Leffler, 1981) thereby increasing information asymmetry between the firm and its investors. Theoretical models (Diamond, 1985), empirical findings (Leuz and Verrecchia, 2000; Lo, 2013), and survey results (Graham, Harvey, and Rajgopal, 2005) lend credence to the argument that managers disclose more voluntarily in order to reduce information asymmetry and improve access to financing. However, disclosure is costly (Verrecchia, 1983; Dye, 1986) and managers resort to increased disclosure only when the expected benefits outweigh the costs. ${ }^{1}$ Moreover, firms often rely on external certifiers and intermediaries (Diamond, 1984; Marinovic and Sridhar, 2015) to provide credible information to investors. ${ }^{2}$ Whether managers voluntarily increase disclosure in response to a reputational damage suffered by an external intermediary can offer insights into the informational role played by the intermediary and the extent to which investors rely on it.

In this paper, I examine whether, when, and the extent to which a loss in reputation of a Credit Rating Agency (CRA) affects the discretionary disclosure practices of corporate bond issuers whose securities are rated by the CRA. Credit rating agencies play a prominent monitoring role in the US bond market. ${ }^{3}$ CRAs gather and analyze information about bond issuers and issue credit ratings that provide an assessment of the creditworthiness of the issuer (the

\footnotetext{
${ }^{1}$ Disclosure costs may include proprietary costs, litigation costs, and administrative costs (Skinner, 1994). Production and commitment costs are some of the other costs associated with increasing disclosure.

${ }^{2}$ Auditors, Rating Agencies, and Banks often play the role of external certifiers, monitors, or intermediaries that reduce information asymmetry between the firm and investors.

${ }^{3}$ A CRA cares about its reputation, has an incentive to become well-informed about the bond issuers' prospects, and consequently engages in monitoring (Tirole, 2006).
} 
entity) or an issuer-specific financial instrument. ${ }^{4}$ Credit ratings are "experience goods" implying that the creditworthiness advisory market is largely reputation based. ${ }^{5}$ The value of credit ratings to the market depends on the reputation of the agency issuing the rating (Langohr and Langohr, 2008).

The role of CRAs is distinct from that of other intermediaries such as banks, equity analysts, and auditors. ${ }^{6}$ Apart from playing a monitoring role, CRAs play an informational role by assimilating private information from firms and conveying long-term focused forward-looking information to investors in the form of publicly available credit ratings. Similar to a firms' preference for Big 4 auditors to certify their financial statements, corporations also prefer their bonds to be rated by agencies that investors trust and value. Ratings issued by reputed CRAs reduce information asymmetry between bond issuers and investors and help mitigate adverse selection problems inherent in lending relationships (Akerlof, 1970; Leland and Pyle, 1977). If ratings cease to be valuable to investors because of a reputation loss suffered by the rating agency, the demand for reliable information to assess the creditworthiness of bond issuers increases. Bond issuers may either resort to other channels of information dissemination to reduce information asymmetry or risk an increase in their cost of issuing debt (Sengupta, 1998; Michels, 2012).

\footnotetext{
${ }^{4}$ The credit rating industry in the US is dominated by three major players: Moody's, Standard \& Poor's, and Fitch. These three rating agencies follow an issuer-pay model and account for more than $95 \%$ of the credit ratings issued (White, 2013). SEC had granted a "nationally recognized" status only to these three agencies prior to 2001. ${ }^{5}$ In economics, experience goods refer to products or services where the value of the product or service is difficult to observe in advance. Consumers purchase the product or service based on the seller's reputation and ascertain its true value only after consumption.

${ }^{6}$ In contrast to auditors who are primarily responsible for assuring the quality of financial reporting, CRAs focus specifically on downside risk and provide more granular forward looking information on probability of default that is comparable across firms in the economy. In contrast to equity analysts, CRAs were exempted from Regulation FD until the passage of the recent Dodd-Frank Act in 2010. Hence, in the post Regulation FD era, while the information provided by equity analysts plays a crucial role in reducing information asymmetry among investors, CRAs help reduce asymmetry between the firm and investors as well. In contrast to banks that serve as a source of financing for firms, CRAs serve purely as an information intermediary.
} 
The extent to which bond issuers respond to reputation shocks suffered by CRAs depends on the information content in credit ratings. ${ }^{7}$ If CRAs incorporate private information about the issuer client into credit ratings and provide incremental useful information to investors and creditors about underlying credit risk of the bond issuer, a reputation loss for the CRA should affect investors' beliefs about the probability of default of the issuer, enhance adverse selection problems, and consequently affect the issuer's ability to access financing. ${ }^{8}$ Prior studies support the argument that firms experiencing information-related shocks are likely to increase their disclosures in order to reduce information asymmetry and influence cost of capital (Diamond, 1985; Leuz and Verrecchia, 2000; Lambert, Leuz, and Verrecchia, 2007; Leuz and Schrand, 2009; Lo, 2013; Balakrishnan et al., 2014). Therefore, I conjecture that corporate bond issuers will increase their disclosure ("Disclosure Substitution Hypothesis") in an attempt to influence the information environment and reset market perceptions when CRAs suffer a loss in reputation.

Alternatively, it is possible that credit ratings are uninformative and investors use ratings issued by major CRAs primarily because prudential regulations require them to do so. ${ }^{9}$ Financial intermediaries such as banks, pension funds, and insurance agencies are subject to regulatory requirements that prohibit them from holding bonds below a certain minimum rating threshold. ${ }^{10}$ Many academics and practitioners argue that CRAs serve primarily as gatekeepers constraining the allocation of regulated capital and not as information intermediaries that provide material new information about the creditworthiness of bond issuers (Partnoy, 2006; Coffee, 2011; White,

\footnotetext{
${ }^{7}$ By information content, I mean the capacity of credit ratings to decrease information asymmetry between bond issuers and investors and mitigate adverse selection issues.

${ }^{8}$ A reputation loss suffered by a CRA increases (decreases) the variance (precision) of investors' assessment of the credit quality of rated firms and potentially leads to a pooling equilibrium where good credit quality firms cannot separate themselves from poor credit quality firms.

${ }^{9}$ For example, federal bank regulators and the SEC have increasingly adopted the use of credit ratings in their respective regulations since the 1930s resulting in an increased use of ratings by capital market participants.

${ }^{10}$ Recently, the SEC has removed references to credit ratings in many Federal rules and statutes pursuant to the DoddFrank Act of 2010. However, state level regulations that govern insurance companies and international regulatory bodies are not subject to Dodd-Frank mandates (Cornaggia and Cornaggia, 2013).
} 
2013). If corporate managers seek ratings predominantly to attract investors (clientele effects) that rely on credit ratings for regulatory reasons (Tirole, 2006; Kisgen and Strahan, 2010; Jeon and Lovo, 2013), then any reputation loss suffered by rating agencies is irrelevant for firms' disclosure decisions. ${ }^{11,12}$ Moreover, if investors demand verification from an external monitor (such as a CRA) regarding credit risk, it may not be feasible for a firm to satisfy this investor need using voluntary disclosure. Even if credit ratings provide some informational value and firms can mitigate adverse selection issues stemming from CRA reputation loss by increasing voluntary disclosure, it is not clear whether the resulting benefits would outweigh the associated disclosure costs. ${ }^{13}$ Under these conditions, I predict no significant increase in disclosure subsequent to a reputation loss suffered by CRAs. Thus, whether a reputation loss to CRAs has a null or increasing effect on disclosure is ultimately an empirical question.

To explore this hypothesis, I exploit two specific regulatory actions that significantly altered the reputation of CRAs. First, I use the regulatory investigation that followed several high profile bankruptcies such as Enron and WorldCom in 2002. Nationally recognized credit rating agencies came under severe criticism as Enron's bonds had been rated "investment grade" by the three major issuer-paid CRAs until a few days before Enron filed for bankruptcy. After Enron and WorldCom filed for bankruptcy, the 2002 Sarbanes-Oxley Act (SOX) directed the SEC to formally investigate the role and function of credit rating agencies (Cheng and Neamtiu, 2009). ${ }^{14}$ This marked the beginning of a lengthy period of regulatory scrutiny (see Figure 1) that involved

\footnotetext{
${ }^{11}$ Besides, additional disclosure may be unnecessary if investors rely on other sources of public and private information to measure the credit risk of an issuer/issue.

${ }^{12}$ Henceforth, I use the terms firms, issuers, issuer clients, bond issuers, corporates, and corporate managers interchangeably.

${ }^{13}$ Managers concerned about releasing proprietary information or setting new disclosure precedents (Graham et al., 2005; Lo, 2013) may prefer not to increase disclosure unless expected benefits are significant.

${ }^{14}$ In October 2002, the Senate Committee on Governmental Affairs issued a report which concluded that the CRAs "displayed a disappointing lack of diligence in their coverage and assessment of [Enron]".
} 
the issuance of a series of reports by the SEC, several congressional and senate hearings, and heavy investor criticism that seriously undermined the reputation of major CRAs. Second, I use the passage of the US Credit Rating Agency Reform Act (CRARA) in 2006 that was aimed at restoring investor confidence in CRAs by enhancing accountability of rating agencies, increasing competition in the rating industry, and improving quality of credit ratings.

To the extent the information shock resulting from such regulatory actions is exogenous to other firms in the economy, the regulation changes provide an ideal setting to examine how a reputation shock to a CRA affects bond issuers' disclosure practices. While most firms with public debt are rated by the three major CRAs, some firms rely only on private debt and certain others are rated by investor-paid rating agencies. ${ }^{15}$ I use a difference-in-differences (DiD) design centered on the passage of the SOX and CRARA Acts to provide evidence on the hypothesis that bond issuers increase disclosure when rating agencies lose reputation and decrease disclosure when investor confidence in the quality of credit ratings improves.

I measure a firm's discretionary disclosure related to credit risk in multiple ways: (i) incidence of management forecasts, (ii) extent of numerical content in the MD\&A section of periodic filings, (iii) proportion of credit risk related words in the MD\&A, and (iv) proportion of credit risk related words in the specific textual context surrounding issuance of forecasts in press releases and conference calls. I find that managers of rated firms are more likely to issue earnings forecasts when rating agencies suffer a reputation loss. To the extent that a loss in rating agencies' reputation creates a pooling equilibrium where investors are unable to distinguish between good and bad credit quality firms, managers of good credit quality firms would resort to increased disclosure (leading to a new separating equilibrium) as benefits from disclosure likely

\footnotetext{
${ }^{15}$ For example, Egan-Jones rating (EJR) agency that follows an investor-pay model was quicker in downgrading the bonds of Enron and WorldCom and consequently did not suffer a reputation loss.
} 
outweigh the costs for such firms. Consistent with this expectation, I find that the increase in disclosure is more pronounced for firms with "investment grade" rating compared to those with "speculative grade" rating. ${ }^{16}$ Additionally, I also find that the increase in disclosure is higher for firms that are rated "low investment grade" (for example, S\&P rating of $\mathrm{BBB}+$ or below) compared to those rated as "mid or high investment grade" (S\&P rating of A- or above). Intuitively, low investment grade firms suffer more from adverse selection problems when ratings are not credible and investors demand more disclosure from such firms. These findings are consistent with credit ratings providing incremental information about creditworthiness of the issuers to market participants and robust to controlling for previously known determinants of disclosure and credit quality.

Managers also increase the quantity of numerical figures in the MD\&A section of their SEC filings to provide more precise information to investors. Additional analyses reveal that disclosure changes occur regardless of whether ratings increased, decreased, or remained constant during the sample period and this alleviates concerns about confounding effects of rating changes on disclosure. Further, I find no disclosure changes for a small sample of firms that were rated only by Egan-Jones Rating Company, a rating agency that did not suffer a reputation shock during the sample period, rendering further credence to the overall findings. I also find that the disclosure effects in response to CRA reputation shocks are persistent, marginally more pronounced for firms with greater uncertainty, and robust to several alternate explanations and econometric techniques.

To further corroborate the disclosure substitution hypothesis, I implement a statistical feature selection algorithm (Manning, Raghavan, and Schutze, 2008) to create a custom "credit

\footnotetext{
${ }^{16}$ Credit ratings follow an alphabet-oriented ordinal rating scale. Investment (speculative) grade ratings correspond to high (low) credit quality. See section 2.1 for more details.
} 
risk" dictionary and analyze the creditor-specific information content in qualitative disclosures. I find evidence that managers provide more qualitative (i.e. textual/non-numeric) information related to credit risk in the MD\&A after CRAs suffer a reputation loss. In addition, I also create a novel dataset comprised of the qualitative information surrounding the issuance of management forecasts in press releases and conference calls (i.e. specific textual context in which the forecast was issued) and find evidence that managers discuss credit risk relevant information more when issuing forecasts during periods of low reputation for the CRAs. This provides support that managers increase the issuance of forecasts with the specific intent of providing more information to creditors for assessing the creditworthiness of the firm when ratings are not credible. Overall, my findings suggest that managers rely on voluntary disclosure as a credible mechanism (Stocken, 2000) to reduce information asymmetry in bond markets.

I contribute to the accounting and finance literatures in several ways. First, while extant research provides insights into factors that influence performance of rating agencies under various conditions (Cheng and Neamtiu, 2009; Bonsall, 2014), there is little evidence on how the credibility of ratings influence a firm's actions. My paper addresses this void. Second, my paper offers direct evidence on the informational role of corporate credit ratings for market participants. Measuring discretionary disclosure changes when there is a reputation shock to CRAs without a concomitant effect on the credit rating of issuers (i.e. holding ratings constant) provides a unique setting to empirically test the informational content in ratings as perceived by issuers. Third, while prior research has examined managerial actions for reputation damage due to a firm's own actions, I provide evidence on how firm managers respond to reputation damage caused by parties external to the firm. Fourth, I add to the emerging literature on the determinants of risk disclosures and provide evidence that managers alter the specific type of risk disclosure that best fills the void created by an information intermediary. Last, I introduce a feature-selection based 
statistical learning algorithm for creating an expanded custom dictionary that can be used by researchers for analyzing credit risk related content in qualitative disclosures.

Section 2 describes related literature and develops the hypothesis. Section 3 describes the research design and sample selection. Section 4 describes the main results, robustness checks, and additional analyses. Section 5 concludes. 


\section{Prior Literature and Hypothesis Development}

\subsection{Overview of Rating Agencies}

An SEC report (SEC, 2003a) on the role and function of credit rating agencies defines a credit rating as a rating agency's opinion, as of a specific date, of the creditworthiness of a particular company, security, or obligation. Credit ratings follow an alphabet-oriented ordinal rating scale. ${ }^{1}$ Based on the ratings issued, securities are classified as "investment grade" or "speculative grade". ${ }^{2}$ In general, credit ratings issued by rating agencies are used by creditors and investors as an independent opinion about the credit risk of the issuer/issue and as a measure of the associated probability of default as well as relative expectations of loss given default (Langohr and Langohr, 2008).

The credit rating industry in the US is dominated by three major players: Moody's, Standard \& Poor's, and Fitch. These three rating agencies account for more than $95 \%$ of the credit ratings issued (White, 2013). While the rating agencies initially adopted an investor-pay model, the advent of photocopiers induced free-riding and rendered such a model unprofitable forcing the CRAs to adopt an issuer-pay model in the early 1970s (Bonsall, 2014). ${ }^{3}$ Even though the issuer-pay model is criticized for creating an independence problem, Bonsall (2014) provides evidence that such a model facilitates increased flow of information from issuer clients to rating agencies resulting in ratings that are more informative to bond market participants. For all of the major CRAs, the majority of the revenue comes from issuers that seek ratings for their specific

\footnotetext{
${ }^{1}$ For example, Standard \& Poor's, one of the major CRAs uses an alphabet scale that runs from AAA to C (sometimes augmented with pluses and minuses) with AAA rated securities having the lowest credit risk.

${ }^{2}$ Bonds rated BBB- or above by S\&P, for example, are considered to be investment grade; those that are BB+ or below are considered to be speculative grade. Speculative grade bonds are also referred to as High Yield Bonds or Junk Bonds.

${ }^{3}$ In an issuer-pay model, bond issuers pay the CRA for ratings. CRAs that follow an investor-pay model rely on subscription fees from consumers of credit ratings (i.e. investors) for revenue.
} 
securities. The need for bond issuers to reduce disclosure costs and for rating agencies to maintain their reputation in the marketplace helps mitigate the independence problem inherent in the issuer-pay model.

Starting from the early 1930s, US prudential regulators required commercial banks to use credit ratings in financial accounting practices related to bonds. ${ }^{4}$ Later, federal bank regulators imposed restrictions that required regulated banks to hold only "investment grade" bonds in their portfolio. After a few decades, regulators of other categories of financial institutions such as insurance companies and pension funds followed suit and began incorporating the use of credit ratings in their respective regulations.

In 1975, the SEC created a new category called NRSRO (Nationally Recognized Statistical Rating Organizations) and formalized the regulatory use of credit ratings by introducing an amendment to the uniform net capital rule that imposed stricter capital adequacy requirements on broker dealers holding non-investment-grade bonds. ${ }^{5}$ In 1976, the three major CRAs were designated as NRSROs. Securities firms were henceforth required to use ratings issued by NRSROs in determining net capital required.

Regulation Fair Disclosure (Reg FD), implemented in October 2000, prohibits US firms from making non-public disclosures to selective investors. However, CRAs were exempted from this requirement and were allowed to confidentially access non-public information from public companies and use such information in assigning credit ratings. In June 2005, US Congress hearings reported that at least 8 Federal statutes, 47 Federal rules, and 100 State laws made references to credit ratings (Langohr and Langohr, 2008).

\footnotetext{
${ }^{4}$ Investment grade bonds are recorded at purchase cost while speculative grade bonds are marked-to-market. ${ }^{5}$ See rule 15c3-1 in SEC Concept Release 33-7085.
} 
In 2001, subsequent to the Enron bankruptcy, NRSROs came under severe scrutiny as Enron's bonds had been rated "investment grade" by the three major CRAs until a few days before the bankruptcy filing. Lack of competition in the credit rating industry was cited as one of the underlying reasons for such failure (AFP, 2002). This led to congressional hearings that questioned the processes used by the SEC in designating and managing NRSROs. Section 702(b) of the Sarbanes Oxley Act passed in 2002 required the SEC to investigate the role and function of CRAs in the operation of securities markets (see Figure 1). In October 2002, the Senate Committee on Governmental Affairs issued a report which concluded that the CRAs "displayed a disappointing lack of diligence in their coverage and assessment of [Enron]”.

On Jan 26, 2003, the SEC issued a report on the role of rating agencies in the capital markets (SEC, 2003a). On Feb 08, 2005, the Senate Committee on Banking, Housing, and Urban Affairs held a hearing titled "Examining the Role of Credit Rating Agencies in the Capital Markets". On Apr 19, 2005, the SEC released a revised rule proposal on the definition of NRSRO. In September 2006, both the House and the US Senate Committee passed the US Credit Rating Agency Reform Act (CRARA) that insisted on transparency and made changes to processes and criteria used by the SEC in certifying and monitoring NRSROs with a view to increasing rating quality, accountability, and competition in the credit rating industry. On Sep 29, 2006, the President signed the "US Credit Rating Agency Reform Act of 2006" into law. The SEC certified three additional CRAs as NRSROs in 2007, and two more in $2008{ }^{6}$

In late 2008, the three major CRAs came under criticism once again for their alleged role in exacerbating the financial crisis by assigning highly optimistic investment grade ratings on structured financial products such as Mortgage Backed Securities (MBS) and Collateralized Debt

\footnotetext{
${ }^{6}$ Japan Credit Rating Agency, Rating \& Investment Inc., and Egan-Jones Rating Company acquired NRSRO status in 2007, followed by LACE and Real Point LLC in 2008.
} 
Obligations (CDO) that were subsequently downgraded to junk status. Consequently, Section 939-939A of the Dodd-Frank Act of 2010 required the complete removal of regulatory references to credit ratings. ${ }^{7}$ Subtitle $\mathrm{C}$ of the Dodd-Frank Act further augmented the CRA Reform Act of 2006 by requiring the SEC to adopt rules applicable to NRSROs in a number of areas. Section 939B of the Dodd-Frank Act required the SEC to revise Regulation FD and remove the exemption granted to CRAs. By early 2013, at least seven more CRAs had acquired NRSRO status, though they were much smaller in size compared to the three major CRAs. ${ }^{8}$ In August 2014, the SEC adopted new requirements for NRSROs in order to enhance governance, protect against conflicts of interest, increase transparency, and increase rating agency accountability.

\subsection{Related Literature}

\subsubsection{Information Content in Credit Ratings}

Prior research has primarily relied on event-study methodology and examined stock and bond market reactions to credit rating events in order to assess whether ratings provide incremental information to capital markets. Pinches and Singleton (1978) study common stock returns surrounding bond rating changes and conclude that both rating upgrades and downgrades are fully anticipated by the market and the information content of bond rating changes is negligible. However, several other studies provide evidence that markets react to rating changes, especially for downgrades more than upgrades. Holthausen and Leftwich (1986) provide initial evidence that downgrades by both Moody's and S\&P are associated with negative abnormal stock returns while upgrades are not. Hand, Holthausen, and Leftwich (1992) examine daily excess bond returns and find similar results. Dichev and Piotroski (2001) analyze long-run stock returns

\footnotetext{
${ }^{7}$ As of September 2015, the SEC has removed references to credit ratings from 32 rules and forms.

${ }^{8}$ As of 2011, the seven smaller CRAs accounted for approximately 3.5\% of the total ratings outstanding (White, 2013).
} 
following bond return changes and find that downgrades are associated with 10-14\% negative abnormal returns in the following year while no reliable abnormal returns are detected following upgrades. They conclude that downgrades are strong predictors of future deterioration in earnings. In contrast, Hull, Predescu, and White (2004) analyze data on credit default spreads (CDS) and find that CDS markets anticipate negative rating events. Norden and Weber (2004) provide a summary of prior studies, conduct their own empirical analysis, and find that both stock and CDS markets anticipate rating downgrades by all three major CRAs.

White (2013) argues that market movements associated with bond rating changes are insufficient to conclude whether ratings provide useful information since market reaction could simply be a consequence of the changed regulatory status of the bond. Hence, in an environment where bond ratings are tightly tied to prudential regulations, collective evidence from prior research is insufficient to conclude whether credit rating changes provide material incremental information to capital market participants for assessing the creditworthiness of the issuer. Extant research (Altman and Rijken, 2004; Beaver et al., 2006) also finds evidence that major CRAs lag the markets in adjusting ratings to reflect changes in issuer circumstances. Further, many of the prior studies that measure the information content in ratings use data prior to year 2000 . The associated findings may not necessarily apply to more recent periods marked by increased criticism of rating agencies, changes in competitive landscape, increased regulatory scrutiny, and serious technological changes impacting the information environment.

\subsubsection{Management Forecasts}

Prior literature (Healy and Palepu, 2001; Beyer, Cohen, Lys, and Walther, 2010) provides a detailed review and discussion of theoretical models and empirical findings related to voluntary 
disclosure. Management forecasts are considered an important form of voluntary disclosure. ${ }^{9}$ Some of the earliest literature on the voluntary disclosure of management earnings forecasts (Foster, 1973; Patell 1976; Penman, 1980) conclude that corporate earnings forecasts, on average, possess information relevant to the valuation of firms and hence to investors' decisions. Pownall, Wasley, and Waymire (1993) find that interim forecasts are significantly more informative than annual projections.

Managers have a motivation congruent with that of shareholders to reduce information asymmetry and maximize firm valuation by issuing earnings forecasts. Prior literature also suggests that management earnings forecasts reveal private information about firm prospects (Beyer et al., 2010), facilitate enhanced monitoring (Nagar, Nanda, and Wysocki, 2003), and allow investors to make inferences about managerial ability (Trueman, 1986; Baik, Farber, and Lee, 2011). A survey by Graham et al. (2005) finds that earnings forecasts are used by management to build a reputation for accurate and transparent reporting.

Release of management forecasts often coincides with the release of other qualitative and contextual disclosures that discuss firm performance (Hutton, Miller, and Skinner, 2003; Nagar et al, 2003). Hutton et al (2003) investigate the role of supplementary statements with management earnings forecasts. Supplementary information are classified as "soft talk" (nonspecific information) or verifiable forward-looking information (specific enough to be compared with subsequent realizations). They find that managers provide soft talk disclosures with similar frequency for good and bad news forecasts but are more likely to supplement good news forecasts with verifiable forward-looking statements in order to bolster credibility of good news forecasts.

\footnotetext{
${ }^{9}$ Other commonly used empirical proxies for voluntary disclosure include survey rankings, researcher-constructed indices, measures based on text analysis, and properties of firms' reported earnings (see Beyer et al. (2010) for a detailed discussion).
} 
Shivakumar, Urcan, Vasvari, and Zhang (2011) demonstrate that credit markets react significantly to management forecast news. They find that these reactions are stronger than reactions to actual earnings news. The forecast news is mainly relevant for firms with poor credit rating and the market effect is more pronounced during periods of uncertainty such as the recent credit crisis. Prior research provides ample evidence that firms alter forecast issuance policy to meet investor needs. Balakrishnan et al. (2014) provide evidence that firms respond to an exogenous loss of equity analysts by providing more timely and informative earnings guidance. Vashishtha (2014) argues that managers reduce issuance of forecasts following covenant violations as shareholders demand less disclosure and delegate monitoring to banks. Lo (2013) provides evidence that borrowers whose banking relationships are threatened by declining bank financial health increase the quantity of management forecasts to attract new funding sources. Frankel, McNichols, and Wilson (1995) show that frequent forecasters access capital markets more often. In summary, management earnings guidance affects stock prices, corporate transactions, credit markets, analyst behavior, cost of capital, and capital market assessment of managerial talent and reputation.

\subsection{Hypothesis Development}

The effect of a reputation shock to a credit rating agency on the bond issuers' disclosure level is theoretically ambiguous because it depends on (i) the issuers' perception of the role played by rating agencies (ii) the information void created by the shock, and (iii) the feasibility of the issuer filling the void using voluntary disclosures without incurring unreasonable costs.

\subsubsection{Why Disclosure May Increase?}

The extent to which bond issuers respond to reputation shocks suffered by CRAs depends on the information content in credit ratings. Apart from reviewing publicly available information, 
major CRAs follow an issuer-pay model and acquire a substantial amount of private information from the issuer client in written form and also by conducting in-depth interviews with the issuer management team before deciding on a credit rating (Langohr and Langohr, 2008). ${ }^{10}$ Kliger and Sarig (2000) note that "paying for ratings may allow firms to incorporate inside information into the assigned ratings without disclosing details to the public at large". Both Moody's and S\&P use material non-public information in the rating process (Bonsall, 2014).

Prior research provides evidence that financial markets react to ratings changes thereby reflecting the information content in credit ratings (Hand et al., 1992; May, 2010). If CRAs incorporate private information into credit ratings and provide incremental useful information to investors about underlying credit risk of bond issuers, a reputation loss for the certifying authority (i.e. CRAs) should exacerbate adverse selection problems and affect investors' beliefs about the credit risk of the issuers. ${ }^{11}$

Theoretical models (Diamond, 1985), empirical findings (Lo, 2013), and survey results (Graham et al., 2005) support the argument that managers voluntarily disclose more in order to reduce information asymmetry and influence cost of capital. I predict that corporate bond issuers will increase their disclosure levels ("Disclosure Substitution Hypothesis") to compensate for the decrease in investors' precision about credit quality, and thereby reduce adverse selection when rating agencies suffer a reputation loss.

\footnotetext{
${ }^{10}$ Rating agencies received an exemption from Regulation FD that remained in effect until October 2010. Section 939B of the Dodd-Frank Wall Street Reform and Consumer Protection Act of 2010 required the SEC to amend Regulation FD to remove the exemption provided to NRSROs.

${ }^{11}$ Prior research shows that credit market information asymmetry affects firms' access to financing, cost of borrowing, and bond yields (Zeibart and Reiter, 1992; Tang, 2009).
} 


\subsubsection{Why Disclosure May Not Change?}

There are at least three reasons why firms may not change their disclosure policies following a loss in CRA reputation. First, critics of CRAs (Coffee, 2011; White, 2013) argue that credit ratings may not provide material new information about the creditworthiness of bond issuers, rendering the loss of rating agency reputation irrelevant for the disclosure decision. Theoretical models (Bolton, Freixas, and Shapiro, 2012; Opp, Opp, and Harris, 2013) predict and empirical studies (Strobl and Xia, 2012; Cornaggia and Cornaggia, 2013) corroborate that the conflict of interest inherent in issuer-pay models lead to inflated and uninformative credit ratings.

Further, existence of a significant demand for credit ratings does not necessarily mean that ratings are informative since such demand may be driven primarily by regulatory requirements. Regulators have historically relied on credit ratings produced by major CRAs for mitigating insolvency risk of financial institutions such as banks and pension funds. For example, regulated institutions simply cannot purchase bonds rated below investment grade by major CRAs. ${ }^{12}$ Partnoy (2006) argues that major issuer-paid CRAs (NRSROs), despite poor performance and offering little informational value, continue to thrive in an oligopolistic market structure devoid of competition since bond issuers require credit ratings from these agencies to attract regulated capital (clientele effects).

Under the clientele effects scenario, bond market reactions to credit rating changes may simply be a response to the changed regulatory status of the bond. ${ }^{13}$ For example, if a CRA downgrades a bond from investment grade to speculative grade, the market may react not because there is incremental information about probability of default in the rating change but because

\footnotetext{
${ }^{12}$ More than $60 \%$ of corporate bonds in the US are held by regulated institutions.

${ }^{13}$ Kisgen and Strahan (2010) provide evidence that regulations constraining bond investments indeed affect bond yields and the firm's cost of debt capital.
} 
many regulated entities can no longer hold the bond or would have to adjust their capital reserve levels to satisfy regulatory requirements based on the new rating (White, 2013).

Second, disclosures may not change if managers feel ratings are somewhat informative to market participants but not significantly enough to justify additional disclosure when CRAs suffer a reputation loss. Rating actions such as downgrades and reviews follow significant events that affect firm value and risk, and such events are observable to all market participants in an efficient market. ${ }^{14}$ Major CRAs seem to lag the markets in adjusting ratings to reflect changes in issuer circumstances (Altman and Rijken, 2004; Beaver et al., 2006). In such an instance, it is rational for managers to believe that market participants rely on other sources of public and private information to assess creditworthiness, thereby rendering any need for additional disclosure moot.

Third, investors who demand verification from an external monitor (such as a CRA) regarding credit risk may not accept voluntary disclosure by firms as a credible substitute because managers have incentives to bias such disclosure (Rogers and Stocken, 2005). Finally, managers may be unwilling to change their disclosure policy if the benefits from increasing disclosure do not outweigh the costs to firms stemming from release of proprietary information and increase in litigation risk. ${ }^{15}$

Under any of these conditions, optimal disclosure by firms is independent of credit ratings and hence a reputation shock to CRAs will have no effect on disclosure.

\footnotetext{
${ }^{14}$ Both stock and credit default swap (CDS) markets seem to indicate a decline in credit quality in advance of actual rating changes and credit watches issued by the three major CRAs (Norden and Weber, 2004). Non-certified investorpaid rating agencies that rely entirely on public information have been shown to be more timely and informative than certified issuer-paid rating agencies in prior empirical research (Beaver et al., 2006).

${ }^{15}$ Managers may choose to adopt alternate strategies (such as increase in capital expenditure or stock buyback) to boost investor confidence in firm prospects.
} 


\section{Research Design and Sample Selection}

To explore my research question, I exploit two specific regulatory actions that had opposite effects on the reputation of the three major issuer-paid CRAs. First, the 2002 SarbanesOxley Act (SOX) launched an SEC investigation of the role and function of rating agencies which revealed that the major CRAs did not do due diligence in assessing creditworthiness and providing timely information that can help investors predict bankruptcies. I use the SEC investigation of CRAs as an event that decreased the reputation of the three major CRAs. Second, the US Credit Rating Agency Reform Act (CRARA) in 2006 introduced reforms in the rating industry to increase investor confidence in CRAs by enhancing accountability of rating agencies, increasing competition in the rating industry, and improving quality of credit ratings. I use the passage of the CRARA as an event that improved the reputation of CRAs. Following prior research (Cheng and Neamtiu, 2009), I define the period between the passage of the SOX act (July 25, 2002) and the CRARA act (September 29, 2006) as one of increased criticism, high regulatory scrutiny, and low reputation for the three major issuer-paid CRAs (see Figure 1).

My first sample (henceforth, SOX sample) includes firm-quarters between January 1, 2001 and December 31, 2003. ${ }^{1}$ I classify the period between January 1, 2001 and July 25, 2002 (i.e. period before the SOX Act) as the PRE period. The period between July 25, 2002 and December 31, 2003 (i.e. period after the SOX Act) is classified as the POST period that corresponds to high regulatory scrutiny and low reputation. Firm-quarters that overlap both the PRE and the POST periods are not included in the sample.

My second sample captures the period surrounding the passage of the US CRA Reform Act (henceforth, CRARA sample) and comprises firm-quarters between October 1, 2004 and June

\footnotetext{
${ }^{1}$ This event window ensures that the sample falls entirely in the post Regulation FD period.
} 
30, 2008. For the CRARA sample, PRE period includes firm-quarters between October 1, 2004 and June 30, 2006. The POST period for the CRARA sample includes firm-quarters between October 1, 2006 and June 30, 2008. ${ }^{2}$

Within each sample, I classify a firm as a "treatment firm" if the firm has obtained a rating from Standard \& Poor's (S\&P), an issuer-paid CRA that suffered a reputation loss. ${ }^{3}$ Firms that rely only on equity financing, private debt, unrated public debt, or public debt with ratings from a rating agency that did not suffer a reputation loss during the sample period (e.g. firms with only Egan-Jones ratings) are classified as "control firms".

To provide evidence on the effect of rating agencies' reputation on the discretionary disclosure of the rated firms, I estimate the following difference-in-differences (Bertrand et al., 2004) empirical specification:

$$
\operatorname{DISCL}_{\mathrm{i}, \mathrm{t}}=\beta_{1}+\beta_{2} \text { POST }_{\mathrm{i}, \mathrm{t}} * \operatorname{TREAT}_{\mathrm{i}, \mathrm{t}}+\beta_{3} \text { CONTROLS }_{\mathrm{i}, \mathrm{t}}+\text {-FIRM }_{\mathrm{i}}+\text { OTIME }_{\mathrm{t}}+\mathrm{v}_{\mathrm{i}, \mathrm{t}}
$$

where, DISCL $\mathrm{i}_{\mathrm{i}, \mathrm{t}}$ is a measure of firm i's discretionary disclosure in quarter t; POST is an indicator variable that takes a value of one for the POST period, and zero otherwise; TREAT is an indicator variable that is set to one if the firm-quarter corresponds to a treatment firm and zero if it corresponds to a control firm; CONTROLS denote a vector of control variables that are known determinants of disclosure such as firm size, firm performance, growth opportunities, future uncertainty, information environment, and other key financial ratios that control for liquidity,

\footnotetext{
2 The event window chosen for CRARA sample ensures that the PRE and the POST periods are symmetric around the CRARA act and the sample period ends in June 30, 2008 to reduce overlap with onset of the financial crisis.

${ }^{3}$ Himmelberg and Morgan (1995) note that virtually all bond and commercial paper issues are rated by S\&P. Hence, I assume that any firm rated by Moody's or Fitch is also rated by S\&P.
} 
leverage, productivity, solvency, and capital turnover; FIRM $_{\mathrm{i}}$, and $\mathrm{TIME}_{\mathrm{t}}$ denote firm and time fixed effects respectively. ${ }^{4}$

The independent variables POST and TREAT are not included in Model (1) as they are subsumed by the presence of time and firm fixed effects respectively. If managers of treatment firms increase discretionary disclosure subsequent to a reputation loss suffered by major CRAs, I expect the coefficient $\beta_{2}$ to be positive for the SOX sample, consistent with "disclosure substitution hypothesis". Similarly, for the CRARA sample, I predict the coefficient $\beta_{2}$ to be negative if managers of treatment firms decrease disclosure when the reputation of rating agencies improves.

I obtain management earnings forecasts data from IBES Company Issued Guidance (CIG) database. Treatment firms are identified based on the availability of S\&P domestic long term issuer ratings (SPLTICRM) in the COMPUSTAT RATINGS database. In addition, I obtain financial statement items for control variables from COMPUSTAT, security returns from CRSP, analyst information from IBES, institutional ownerships from Thomson Financial 13F Institutional Holdings database, SEC filings from EDGAR, and management guidance reports from Thomson Reuters Street Events. Details related to the measurement of control variables and the motivation for including them in my empirical specification are described in Appendix A. Sample size is determined by the availability of data for all variables included in the model for the duration of the sample period which results in 16,214 firm-quarter observations for the SOX sample and 27,344 firm-quarter observations for the CRARA sample. The SOX (CRARA) sample comprises of 6817 (10250) treatment observations and 9397 (17094) control observations.

${ }^{4}$ I control for time fixed effects by including an indicator variable for every calendar year-quarter. 


\section{Empirical Results}

For my main tests, I measure a firm's disclosure using an indicator variable (FCAST) to denote the incidence of management earnings forecasts during a fiscal quarter and use it as the primary outcome variable. Alternate measures of disclosure based on qualitative content in MD\&A, Press Releases, and Conference Call transcripts and the associated empirical results are described in section 4.6.

\subsection{Descriptive Statistics}

Table 1 Panel A provides the descriptive statistics for the variables used in the empirical analyses, for the treatment and control firm-quarters separately. ${ }^{1}$ I winsorize all continuous variables at the $1 \%$ and $99 \%$ levels to mitigate the influence of outliers.

Relative to treatment firms (i.e. firms rated by $\mathrm{S} \& \mathrm{P}$ ), controls firms, on average, have a lower incidence of management forecasts. In particular, I find that about $36 \%$ of treatment firms and $25 \%$ of control firms issue earnings forecasts. Treatment firms have larger size, higher bookto-market ratio, lower volatility in returns, larger analyst following, and higher leverage ratio. This is not surprising since many of the larger firms rely on public debt and are rated by major credit rating agencies, while smaller firms have lesser or almost no public debt, more private debt, and are less likely to be rated by major CRAs. About $68 \%(67 \%)$ of the treatment (control) firms have at least one institutional investor that holds more than $5 \%$ of the shares.

The financial ratios differ in predictable ways for treatment firms relative to their control counterparts. The median leverage ratio (LEVTA) is higher (62\% versus $37 \%$ ) for firms rated by S\&P. Moreover, control firms have relatively lower earnings as a percentage of total assets

\footnotetext{
${ }^{1}$ Considering the SOX and CRARA samples together, there are 17067 (i.e. 6817+9397) treatment firm-quarter observations and 26491 (i.e. 9397+17094) control firm-quarter observations.
} 
(median EBITTA is $1.8 \%$ for control firms versus $2.2 \%$ for treatment firms) and higher market value of equity as a percentage of total liabilities (median MVETL is 4.618 versus 1.437).

In Table 1, I report Pearson and Spearman correlations for the SOX (Panel C) and the CRARA (Panel D) samples separately. The main variable of interest, FCAST, is significantly correlated with almost all control variables, with the expected signs. In both the samples, TREAT is positively correlated with FCAST. On the other hand, POST is uncorrelated with FCAST in the SOX sample (-0.001; p-value 0.898) and negatively correlated with FCAST in the CRARA sample (-0.035; p-value <0.01). LEVTA exhibits a strong positive correlation with TREAT in both samples, as expected, since highly levered firms are more likely to have public debt and be rated by major rating agencies. LEVTA is positively correlated $(0.044$; p-value $<0.01)$ with FCAST in the SOX sample and negatively correlated $(-0.026$; p-value < 0.01$)$ with FCAST in the CRARA sample. I find that all other financial ratios are significantly correlated with FCAST across both the samples bearing similar signs.

\subsection{Empirical Validation of Reputation Shocks}

To validate whether the regulatory events altered the reputation of CRAs as perceived by market participants, I analyze the stock market reaction to bond rating changes before and after each event. I obtain corporate bond rating changes data from Mergent Fixed Income Securities Database (FISD) and stock returns from CRSP. I exclude Yankee bonds and bonds issued through private placement. Based on prior research (Jorion, Liu, and Shi, 2005), I estimate the following specification to ascertain the changes in information content of ratings:

$$
\mathrm{AAR}_{\mathrm{j}}=\lambda_{0}+\lambda_{1} \text { POST }_{\mathrm{j}}+\lambda_{2} \mathrm{ABS}_{-} \text {RAT_CHG } \mathrm{j}_{\mathrm{j}}+\lambda_{3} \mathrm{IGRADE}_{\mathrm{j}}+\lambda_{4} \mathrm{DAYS}_{-} \mathrm{DHG}_{\mathrm{j}}+\varepsilon_{\mathrm{j}}
$$


where for bond $\mathrm{j}$, AAR is the absolute abnormal return computed as the absolute value of the bond issuer's daily stock return minus the value-weighted market index return on the effective date of the rating change; ABS_RAT_CHG is the absolute magnitude of the rating change - i.e. the difference in cardinal values (for example, 27 for rating AAA and 7 for rating $\mathrm{C}$ ) of the new and old ratings for the same bond; IGRADE is an indicator variable set to 1 if the bond rating change crossed the investment-speculative boundary and 0 otherwise; and DAYS_CHG is the natural logarithm of the number of days since the previous rating change in the same direction. ${ }^{2}$

In the above specification, the variable of interest POST measures the magnitude of change in investor response to rating changes around the reputation shocks. I expect the coefficient on POST to be negative for the SOX sample since a loss of reputation of rating agencies will decrease investor reaction to rating events. I expect the coefficient on POST to be positive for the CRARA sample as increased rating reliability will lead to an increase in market response to rating events. ABS_RAT_CHG controls for the magnitude of rating change as larger magnitudes should impact stock prices more. I do not have specific predictions for the coefficients on IGRADE and DAYS_CHG since rating revisions that cross the investmentspeculative boundary (i.e IGRADE=1) and those that occur after a long gap (i.e. larger value of DAYS_CHG) may or may not be anticipated by the market and hence the informational content of such events is ambiguous.

I estimate equation (2) for the SOX and CRARA samples separately, after partitioning the observations in each sample based on the direction of rating change (i.e. rating upgrades vs. downgrades) and the results are documented in Table 2 Panel A. For the downgrade regression (see columns (1) and (3)), I find that the coefficient on POST is negative (-0.0174) for the SOX

\footnotetext{
${ }^{2}$ Number of days since previous revision is set to 1200 if there are no prior bond revisions in the same direction within the sample period.
} 
sample and positive (0.0196) for the CRARA sample as expected with both coefficients significant at the $1 \%$ level. The coefficients for the upgrade regression (see columns (2) and (4) of Table 2 Panel A) are also of the expected signs and significant at the $1 \%$ level, albeit with smaller magnitudes (-0.0094 for the SOX sample and 0.0094 for the CRARA sample). It is interesting to note that the coefficients on ABS_RAT_CHG are positive and significant for the downgrade regressions in both samples but insignificant and almost zero for the upgrade regressions. This finding is consistent with prior research (see Norden and Weber (2004) for a summary) that generally report negligible market reactions to rating upgrades.

As a robustness check, I also estimate an alternate specification where the outcome variable is the signed abnormal return (SAR) during bond rating changes. In this specification, the variable of interest, POST, captures the direction of change in investor response to rating changes around the reputation shocks. I expect the coefficient on POST to be positive (negative) for rating downgrades (upgrades) in the SOX sample and negative (positive) for rating downgrades (upgrades) in the CRARA sample. ${ }^{3}$ Results, documented in Table 2 Panel B, are as expected. For the SOX sample, the coefficient on POST is positive (0.0078) for rating downgrades and negative (-0.0061) for rating upgrades. For the CRARA sample, the coefficient on POST is negative ($0.0165)$ for rating downgrades and positive $(0.0022)$ for rating upgrades. Overall, the results in Table 2 provide support for the validity of reputation shocks examined in this paper. ${ }^{4}$

\footnotetext{
${ }^{3}$ A reputation loss suffered by CRAs should make market reaction to rating downgrades less negative and upgrades less positive. On a similar note, a reputation restoration should make investors react more negatively to downgrades and more positively to rating upgrades as ratings become more reliable in the POST period.

${ }^{4}$ Inferences are unaffected if I use alternate 3 -day $(-1,0,+1)$ window for computing the abnormal returns surrounding rating changes. However, such longer windows are prone to interference from other events that may impact returns such as firm-specific press releases (Holthausen and Leftwich, 1986).
} 


\subsection{Main Results}

I first estimate equation (1) using Ordinary Least Squares (OLS) estimation for the SOX sample, and the results are reported in column (2) of Table $3 .^{5}$ The coefficient on the interaction term POST $\mathrm{x}$ TREAT, 0.03 , is positive and significant at the 5\% level. This suggests that the change in the incidence of management forecasts between PRE (high-reputation) and POST (lowreputation) periods for the treatment firms is about 3\% higher than that for control firms. Hence, treatment firms increased the issuance of management forecasts more than control firms did when entering a period of high regulatory scrutiny and low reputation for rating agencies.

The results from estimation of equation (1) for the CRARA sample are reported in column (5) of Table 3. The coefficient on the interaction term POST x TREAT, -0.056 , is negative and significant at the $1 \%$ level. This suggests that the change in the incidence of management forecasts between PRE (low-reputation) and POST (high-reputation) periods for the treatment firms is about 5\% lower than that for control firms. Or, in other words, treatment firms did not increase the issuance of management forecasts as much as the control firms did when entering a period of high reputation for CRAs.

Collectively, these results provide evidence in favor of the "disclosure substitution hypothesis". That is, investors demand more disclosure from rated firms when the credibility of ratings is questionable and managers find it in their best interests to disclose more. The change in the likelihood of issuing management forecasts for treatment firms compared to that for control firms is also economically significant. A 3 to 5 percent change in the likelihood of issuing management forecasts represents approximately 8 to 14 percent of the unconditional probability

\footnotetext{
${ }^{5}$ I use Ordinary Least Squares (OLS) estimation even though the dependent variable is dichotomous since inclusion of firm fixed effects in non-linear probit or logit models with panels of relatively smaller lengths can bias the coefficients due to the incidental parameters problem (Greene, 2004). In untabulated tests, I find that all my inferences are unaffected by estimating non-linear logit models using industry fixed effects.
} 
of issuance of forecast by a treatment firm in my sample. This magnitude is almost identical to the change in the likelihood of forecast issuance following a covenant violation (Vashishtha, 2014) or a loss of coverage by an equity analyst (Balakrishnan et al., 2014) documented by prior research.

\subsection{Cross-Sectional Variations in Disclosure Changes}

\subsubsection{Partition Based on Rating Changes in Time-series}

It is possible that firms alter disclosure levels when ratings change, regardless of whether rating agencies suffer a reputation loss. Although I control for key financial ratios that are associated with creditworthiness and default likelihood (Altman, 1968; Beaver, McNichols, and Rhie, 2005; Shumway, 2001) when estimating equation (1), any incremental effect of rating changes on disclosure levels can impact the inferences. To account for the effects of rating

changes, I estimate equation (1) by partitioning the treatment firms based on whether they experienced a rating increase (RAT_INCR), no change in rating (RAT_CONS), or a rating decrease (RAT_DECR) during the sample period and report the results in Table 4.

I estimate equation (1) both before and after including control variables. Results for the SOX sample are reported in columns (1) and (2), whereas results for the CRARA sample are reported in columns (3) and (4). For both the SOX and the CRARA samples, the coefficient on the interaction term, POST x RAT_CONS, is significant, and of the expected sign in all estimations. This suggests that the disclosure effect of reputation shocks to rating agencies exists even for treatment firms that did not experience any rating change during the sample period.

The coefficient on POST x RAT_DECR is almost zero for the SOX sample. One possible interpretation of this finding is that rating decrease conveys bad news about a firm's prospects, and it is conceivable that investors do not demand additional disclosure from treatment firms for 
verification (compared to control firms) even though the source (i.e. the rating agency) has become less credible during the POST period. In other words, if bad news is credible "as is", there is no need for managers of a firm to incur additional cost and provide disclosures that would substitute for the information provided by the external monitor.

The results from the estimation using the CRARA sample further support this interpretation. Unlike the SOX sample, the CRARA sample corresponds to a positive shift (i.e. low to high) in the reputation of CRAs. The results in columns (3) and (4) provide evidence that there is a significant decrease in disclosure only when ratings decrease but not when ratings increase between the PRE and the POST periods. Or, in other words, the need for increased disclosure persists for good news (i.e. rating increase) that require a higher verifiability but not for bad news (i.e. rating decrease). These results are also consistent with the notion that investors demand additional supporting information from issuers when ratings increase because of the conflict of interest inherent in issuer-pay models that incentivizes CRAs to inflate ratings.

\subsubsection{Partition Based on Credit Ratings}

A loss of credibility in ratings results in a pooling equilibrium where investors are unable to distinguish firms with good credit quality from those with bad credit quality on the basis of ratings (Akerlof, 1970). Consequently, managers of good firms are more likely to signal the market about their firms' credit quality using voluntary disclosures (Spence, 1973) and improve their cost of issuing debt. To the extent firms classified as "investment grade" generally includes a higher concentration of good credit quality firms, I expect the increase in disclosure to be more pronounced for "investment grade" firms compared to "speculative grade" firms. ${ }^{6}$ I estimate

\footnotetext{
${ }^{6}$ I assume here that irrespective of the credibility of ratings as perceived by investors, the distribution of ratings in the economy (i.e. investment vs. speculative grades) is broadly representative of the distribution of credit quality among firms for the purposes of my empirical analysis.
} 
equation (1) after partitioning the treatment firms into investment and speculative grade and report the results in Table 5. For the SOX sample, the coefficient on POST x INV, 0.045, is positive and significant at the $1 \%$ level (see column (1)) and the corresponding coefficient for the “speculative grade", POST x SPEC is insignificant.

Since investment grade classification includes firms with significant disparity in credit quality, I further sub-divide "investment grade" firms into high (AA- or above), medium (A+, A, $\mathrm{A}-)$, and low (BBB+ or below) categories and estimate equation (1). ${ }^{7}$ The results of this estimation are reported in column (2) of Table 5. The coefficient on the interaction term is positive and significant for the low investment grade sample. The coefficients on the interaction terms for the medium and high investment grade samples, while positive as expected, are not significant at conventional levels. This is intuitive since low investment grade firms are impacted the most if ratings are less credible as they are the closest to speculative grade territory and investors may be unable to clearly distinguish such firms from junk rated firms. As a result, managers of "low" investment grade rated firms have higher incentives to disclose more when rating agencies suffer a reputation loss.

Results for the CRARA sample, outlined in columns (3) and (4) of Table 5, suggest that all treatment firms decrease discretionary disclosure compared to control firms when rating agencies regain their reputation. The magnitude of decrease is more pronounced for investment grade firms compared to speculative grade firms, as expected, albeit the difference is not statistically significant.

\footnotetext{
${ }^{7}$ For example, while S\&P AAA rated bonds correspond to an average default probability of $0.02 \%$, the average default rate of BBB- rated bonds is about $0.90 \%$ (i.e. 45 times more compared to AAA) (Langohr and Langohr, 2008).
} 


\subsubsection{S\&P versus Egan Jones Ratings}

Egan Jones Rating Company (EJRC) follows an "investor-pay” model and hence receives no fees from issuers of entities it rates. Egan-Jones relies on public information for assessing the credit worthiness of firms and their security instruments. EJRC has received much positive publicity on account of issuing rating downgrades for Enron and WorldCom prior to their bankruptcy filings in a much timelier manner and did not suffer any reputation loss (Langohr and Langohr, 2008). ${ }^{8}$ I predict that firms that obtained ratings from EJRC instead of S\&P will not alter their disclosure levels significantly as a result of the reputation shocks suffered by major CRAs. To ascertain this, I estimate equation (1) by augmenting the specification with an additional indicator variable, IsEJRRated, which is set to one for firms that were rated by EJRC during the sample period and zero otherwise. I also include an interaction term, POST $\mathrm{x}$ IsEJRRated, to capture the change in disclosure for EJR rated firms around reputation shocks as compared to control firms.

Results tabulated in Table 6 show that the coefficient on the interaction term POST $\mathrm{x}$ IsEJRRated is insignificant for both the SOX and the CRARA samples. This suggests that firms that were rated only by EJRC did not alter their disclosure levels after the shocks whereas firms rated by S\&P did. This provides further credence to the argument that firms' disclosure policies change when the reputation of the rating agency changes.

\subsubsection{Partition Based on R\&D Expenses}

In this section, I examine whether treatment firms that engage in $R \& D$ react differently to CRA reputation shocks when compared to treatment firms with no R\&D expenses. On the one

\footnotetext{
${ }^{8}$ Enron was put on a negative watch by EJRC as much as 110 days before the bankruptcy filing (Langohr and Langohr, 2008).
} 
hand, firms that engage in $R \& D$ are likely to face higher proprietary costs related to disclosure and hence may not alter their disclosure patterns significantly in response to CRA reputation shocks (Verrecchia, 1983). On the other hand, firms engaging in R\&D are associated with higher information asymmetry and future uncertainty (Aboody and Lev, 2000; Boone and Raman, 2001; Kothari, Laguerre, and Leone, 2002), and hence investors may demand more (less) disclosure from such firms when ratings become less (more) reliable. Also, if rating agencies acquire soft information related to $\mathrm{R} \& \mathrm{D}$ from clients and incorporate the same into credit ratings, whether voluntary disclosure can substitute for such information is ultimately an empirical question. To account for the effects of $R \& D$ on disclosure changes, I create two indicator variables TREAT_RD and TREAT_NRD. TREAT_RD is set to one if the observation corresponds to a treatment firm that incurred non-zero $\mathrm{R} \& \mathrm{D}$ expenses during the fiscal year and zero, otherwise. TREAT_NRD is set to one if the observation corresponds to a treatment firm that incurred no R\&D expenses during the fiscal year and zero, otherwise. ${ }^{9}$ I estimate equation (1) by replacing POST $x$ TREAT with the corresponding interaction terms created using the indicator variables (i.e. POST x TREAT_RD and POST x TREAT_NRD) and report the results in Table 7.

For the SOX sample, column (1) shows that the coefficient on POST x TREAT_RD is positive (0.044) and significant at the 5\% level. However, the coefficient on POST $x$ TREAT_NRD is insignificant. In column (2), I estimate equation (1) for the SOX sample after including industry-year fixed effects since $R \& D$ expenses may likely be impacted by macroeconomic factors. The coefficient on POST x TREAT_RD continues to remain positive (0.048) and significant at the 5\% level. The coefficient on POST x TREAT_NRD is also positive

\footnotetext{
${ }^{9}$ In my sample, there are only 35 observations for which R\&D expenses data is missing in Compustat database. Setting the missing values to zero or excluding the observations corresponding to missing data does not alter the results.
} 
(0.038), albeit of a lower magnitude. The difference between the coefficients on the two interaction terms, however, is not statistically significant at the conventional levels. For the CRARA sample, columns (3) and (4) show that the coefficient on POST x TREAT_RD is negative, as expected, and significant at the $1 \%$ level. However, the coefficient on POST $\mathrm{x}$ TREAT_NRD is negative in all estimations but insignificant after including industry-year fixed effects.

Overall, it appears that treatment firms engaging in R\&D alter their disclosure at least as much or more than treatment firms without $R \& D$ expenditure in response to CRA reputation shocks. This result is also consistent with prior research (Merkley, 2014) which finds that firms alter R\&D related disclosure in response to investors' changing information demands.

\subsubsection{Partition Based on Immediate Financing Needs}

Prior studies (Lo, 2013) argue that firms' need for financing provides managers an incentive to disclose more forward-looking information to potential investors. In this section, I test whether disclosure effects in response to CRA reputation shocks vary based on a firm's immediate need for financing. I measure a firm's immediate need for financing by computing the ratio of long-term debt due within one year to total long term liabilities. A higher value for this ratio implies that a larger portion of the firm's debt is maturing in the short-term (i.e. within one year) and hence more pronounced is the need for immediate financing from an ex-ante perspective. To partition the treatment firms into two groups based on whether the firm has a high or low need for immediate financing, I create indicator variables - TREAT_HI_FIN and TREAT_LO_FIN. TREAT_HI_FIN (TREAT_LO_FIN) is set to one if the observation corresponds to a treatment firm and the ratio of long-term debt to total liabilities is above (below) the median, and zero otherwise. I replace my variable of interest, POST x TREAT, with the 
interaction terms POST x TREAT_HI_FIN and POST x TREAT_LO_FIN, and estimate equation (1).

For the SOX sample, the coefficient on POST x TREAT_HI_FIN is positive $(0.061)$ and significant at the $1 \%$ level (see column (1) Table 8). The coefficient on POST x TREAT_LO_FIN is also positive (0.026), but much lower in magnitude and not significant at the conventional levels. This suggests that the increase in disclosure in response to CRA reputation loss is almost entirely driven by firms that have a higher immediate need for financing. However, for the CRARA sample, the coefficients on both interaction terms are negative, almost identical in magnitude, and significant at the $1 \%$ level. This suggests that improvement in CRA reputation does not induce firms with higher need for immediate financing to reduce their disclosure any more than firms that do not have such a need, potentially because more transparency improves access to financing. Overall, I find evidence that investors demand more disclosure from firms in need of financing, when CRAs suffer a reputation loss.

\subsection{Additional Analyses}

\subsubsection{Timing of Changes in Disclosure}

A key assumption in my study as with any DiD analysis is that the treatment and control firms share parallel trends in disclosure absent changes in CRA reputation. Under this assumption, the DiD estimates represent the causal effect of CRA reputation on firm disclosure. In order to validate this assumption, I estimate equation (1) after including additional indicator variables for prior periods and associated interaction terms, and report the results in Table 9. For the SOX sample, BEFORE(-1) (BEFORE(-2)) is an indicator variable that equals one for firmquarter observations one period (two periods) before the treatment quarter, and zero otherwise. The coefficients on BEFORE(-1) x TREAT and BEFORE(-2) x TREAT are both insignificant. 
However, the coefficient of interest, POST $_{t} \mathrm{x}$ TREAT, is positive (0.034) and significant at the $5 \%$ level (see column (1) of Table 9), confirming that treatment firms increase their disclosure levels in the POST period and not in the PRE period when compared to control firms. This provides support for the parallel trend assumption inherent in difference-in-differences designs.

For the CRARA sample, BEFORE(-1) and BEFORE(-2) correspond to the periods immediately preceding the CRARA act. The coefficients on the interaction terms, BEFORE(-1) $\mathrm{x}$ TREAT and BEFORE(-2) x TREAT, are both insignificant, providing support for parallel trends in the PRE period. The coefficient on POST $_{t}$ x TREAT (see column (3) of Table 9) is negative ($0.055)$ and significant at the $1 \%$ level.

Next, I test whether the disclosure effects are short-lived or persist into the POST period. To evaluate persistence, I create indicator variables- $\operatorname{AFTER}(+1), \operatorname{AFTER}(+2)$, and $\operatorname{AFTER}(+3)$ - that equal one for firm-quarter observations in the first period, second period, third period and beyond, after the reputation shocks respectively, and zero otherwise. I estimate equation (1) after replacing POST $\mathrm{x}$ TREAT with the corresponding interaction terms using these indicator variables in order to assess the disclosure changes in specific portions of the POST period for the treatment group compared to the control group. The results of this estimation are reported in columns (2) and (4) of Table 9. For the SOX sample, the coefficients on the interaction terms, $\operatorname{AFTER}(+\mathrm{N}) \quad \mathrm{x}$ TREAT, are all positive and significant at the conventional levels (see column (2)). The corresponding coefficients are negative for the CRARA sample (see column (4)) and significant at the $5 \%$ level or better. Overall, these results provide evidence that effects persist well into the POST period in both samples. 


\subsubsection{Robustness Checks}

In this section, I describe additional tests to mitigate spurious effects, if any, arising due to dissimilarities in covariates between treatment and control sample. Columns (1) and (4) of Table 3 show the results from estimation of equation (1) without including control variables, for the SOX and CRARA samples respectively. The sign, magnitude, and significance of the coefficients on the interaction term POST $\mathrm{x}$ TREAT, in both samples, are similar to those in earlier estimations that included control variables (i.e. columns (2) and (5) of Table 3). This is intuitive because the hypothesized effects are not expected to be highly sensitive to dissimilarities between treatment and control groups in a difference-in-differences estimation as long as the parallel trends assumption is satisfied. To mitigate the impact of any unknown macroeconomic event on the inference, I estimate equation (1) after controlling for industry-year interaction fixed effects (in addition to firm and time fixed effects) and the results are tabulated in columns (3) and (6) of Table 3. The coefficient of interest, POST x TREAT, in both the SOX and the CRARA samples are almost identical in magnitude differing only in sign. For both samples, the coefficients are significant at the $1 \%$ level. This finding provides assurance that my main results are not driven by unknown macroeconomic changes in specific years that affect firm disclosure in specific industries.

To further alleviate concerns about any spurious effects due to significant differences in size and leverage between treatment and control firms, I repeat the estimation of equation (1) using a matched sample. Specifically, I use a "nearest-neighbor matching with caliper and replacement" algorithm to match treatment and control firms based on size, leverage, year, and industry. ${ }^{10}$ I ensure that both size and leverage do not differ by more than $30 \%$ between

\footnotetext{
${ }^{10}$ This procedure ensures that size and leverage are not significantly different between treatment and control firms.
} 
counterparts in a matched pair leading to a much smaller sample size of 4,611 firm-quarters for the SOX sample and 9,135 firm-quarters for the CRARA sample. ${ }^{11}$ Results of this estimation are shown in columns (1) and (3) of Table 10 Panel A, for the SOX and CRARA samples respectively. The coefficient of interest, POST x TREAT, is positive for the SOX sample (0.064) and significant at the $10 \%$ level. For the CRARA sample, the coefficient is negative $(-0.036)$ and significant at the $10 \%$ level. The magnitudes of the coefficients on all control variables (untabulated) are comparable between full sample estimations and the matched sample estimations.

As an additional robustness check, I also implement entropy balancing, a multivariate reweighting method described in Hainmueller (2012) that reweights the observations in control group to match the covariate moments in treatment group. After matching the covariates in control and treatment groups on both first and second moments, I estimate equation (1) and report the results in Table 10. The coefficient of interest, POST x TREAT, is positive for the SOX sample (0.025) and significant at the 5\% level (see column (2) in Panel A). For the CRARA sample, the coefficient is negative (-0.032) and significant at the $1 \%$ level (see column (4) in Panel A). The first two moments (i.e. mean and variance) for key covariates in the treatment and control groups are presented in Table 10 Panel B.

Overall, the results from estimations using alternate matching techniques confirm the findings from earlier estimations using the full sample.

\footnotetext{
${ }^{11}$ A matched sample of smaller size makes the treatment and control groups more similar but reduces power in estimation leading to higher standard errors and lower statistical significance for the hypothesized effects (Kinney, 1986). Estimations using non-matched random samples of smaller sizes show similar reduction in power (untabulated).
} 


\subsubsection{Confounding Effects due to Arthur Andersen Audit Clients}

Prior studies (Chaney and Philipich, 2002; Cahan, Chaney, Jeter, and Zhang, 2013) find that damaging revelations regarding Arthur Andersen's role in the Enron accounting fraud led to negative capital market effects for Andersen clients. In January 2002, Arthur Andersen acknowledged that its employees had destroyed documentation related to Enron audit. While Chaney and Philipich (2002) find that this event led to a negative market reaction for Arthur Andersen (henceforth, AA) clients, Nelson et al. (2008) argue that such findings are attributable to other confounding effects such as decline in oil prices around the same time along with differences in industry composition of AA clients relative to other Big 4 clients. Leuz and Schrand (2009) argue that AA clients likely experienced cost of capital shocks due to Enron collapse leading to increases in disclosure levels.

Although the event I study, i.e. the passage of the SOX act, occurs more than six months after Enron bankruptcy (December, 2001) and the damaging revelations related to Arthur Andersen (January, 2002), it is possible that the increased disclosure response by rated firms in my SOX sample is confounded by other effects such as increased disclosure by AA clients following Enron collapse. Results documented in Table 9 provide evidence that the increase in disclosure occurs only in the POST period following SEC investigation and not in the PRE period. This provides some assurance that the disclosure effect is more likely due to the loss of reputation of CRAs following the SEC investigation. To further mitigate confounding effects due to AA clients, I estimate equation (1) after excluding firms that were audited by Arthur Andersen from my SOX sample and present the results in Table 11. First, I exclude observations corresponding to fiscal years where the firm engaged AA as the auditor, and report the results in column (1). The coefficient on POST x TREAT is positive (0.039) and significant at the 5\% level. Second, in addition, I exclude those observations where the firm had engaged AA as the 
auditor in the fiscal year prior to the year corresponding to the observation, and report the results in column (2). The coefficient on POST x TREAT continues to remain positive (0.036) and significant at the $5 \%$ level. This provides support that the increase in disclosure documented in this study is not driven by AA clients responding to cost of capital effects following the Enron shock.

\subsection{Content Analytics and Alternate Outcome Variables}

In this section, I evaluate whether managers rely on alternate communication channels to inform investors about credit risk subsequent to a CRA reputation loss. More specifically, I study two channels, (1) MD\&A section of periodic SEC filings, and (2) qualitative statements accompanying management forecasts in press releases and conference calls, that managers often rely on to provide voluntary disclosures related to firm performance and future prospects. Managers have considerable discretion over both the form and content of the information conveyed to capital market participants through these channels.

\subsubsection{MD\&A Analysis}

Do managers use the MD\&A as a supplementary channel to inform investors about the creditworthiness of the firm? Prior research (see Cole and Jones, 2005, for a summary) documents that the information in the MD\&A section of SEC filings (such as 10-K and 10-Q) is value relevant, predicts future accounting outcomes, and is useful to investors in making rational investment and credit decisions. Mayew et al. (2015) document that textual disclosures in the MD\&A provide incremental information beyond financial ratios, market-based variables and even the auditor's going concern opinion in predicting a firm's ability to continue as a going concern. The SEC in a 2003 release (SEC, 2003b) indicates that the MD\&A is a critical component of communication with investors. 
To examine whether CRA reputation shocks affect the disclosure by firms in the MD\&A section of their periodic SEC filings, I use two alternate proxies for measuring discretionary disclosure based on the information contained in the MD\&A and estimate equation (1). The first proxy, PROPNUM\%, is measured as the proportion of numbers in the MD\&A (Vashishtha, 2014). Greater use of numeric terms in disclosures provides more precise information to investors and increases the credibility of qualitative information contained in the MD\&A (Demers and Vega, 2014). ${ }^{12}$ The second proxy, PROPCRD\%, is measured as the proportion of words that indicate credit risk related information. Measurement of the second proxy, PROPCRD\%, involves textual analysis of the MD\&A content using a custom dictionary specifically constructed to identify credit risk related words and phrases used by management.

To compute the proxy outcome variables, I adopt the following procedure. First, I construct a PERL script to automatically download and extract the MD\&A section from the quarterly and annual filings on SEC EDGAR website that correspond to the firm-quarter observations in my sample. The script also ensures that all HTML tags are stripped and the extracted content from each filing is saved in a separate text file for subsequent analysis. In order to ensure that the MD\&A extractions are accurate, I perform the following 2 additional steps: (1) I sort the extracted text files with MD\&A content based on file size and isolate the ones that are either above 150k or below 10k in size, examine their contents, and if required I manually extract the MD\&A section from EDGAR directly to ensure accuracy ${ }^{13}$, and (2) I randomly examine

\footnotetext{
${ }^{12}$ In a related study, Hirst, Koonce, and Venkataraman (2007) use management forecasts setting to provide evidence that managers can credibly communicate with market participants by providing more disaggregated information.

${ }^{13}$ PERL code relies on text based delimiters (e.g. item number and section title) in order to identify the start and end of the MD\&A section in 10-Q and 10-K filings. In some rare cases, the extracted section may include portions outside the desired section, if the delimiters fail to match correctly. Similarly, in some cases, the MD\&A portion may be partially cut off or non-existent (for example, MD\&A may be incorporated in the filing by reference and the actual content may be part of a separate exhibit). These scenarios lead to situations where the file sizes are either too large or too small. Manual extraction of MD\&A for these cases mitigates measurement error.
} 
about $10 \%$ of the remaining text files to ensure that the MD\&A sections have been correctly extracted. ${ }^{14}$

Second, I use a statistical learning approach based on a feature selection algorithm (Manning, Raghavan, and Schutze, 2008) to construct a comprehensive custom dictionary comprising of approximately 275 words and phrases that capture credit risk related information. ${ }^{15}$

Third, I construct additional PERL scripts that use the text files and the custom dictionary as inputs and compute the following: (1) total number of words in the file, (2) total number of dictionary words and phrases in the file, and (3) total number of numerical figures in the file. I calculate the proxy variables, PROPNUM\% and PROPCRD\%, by computing the appropriate ratios as defined previously. Descriptive statistics are provided in Panel B of Table 1. On average, treatment firms have a higher percentage of numbers in the MD\&A (9\% vs $8 \%$ ) compared to control firms. Similarly, while $5.8 \%$ of the words in the MD\&A are credit risk related for the treatment firms, about $5.2 \%$ of the words are credit risk related in the MD\&A of control firms.

For ease of interpretation, I estimate equation (1) using the logarithm of the two alternate proxies, LOGPROPNUM and LOGPROPCRD, as outcome variables and tabulate the results in Table $12 .{ }^{16}$ In the estimation using LOGPROPNUM as the outcome variable, the coefficient on POST $x$ TREAT, is positive (negative) and significant at the $1 \%$ level for the SOX (CRARA) sample as expected (see columns (1) and (3) of Table 12). This is consistent with the findings reported earlier using the incidence of management forecasts (FCAST) as the outcome variable.

\footnotetext{
${ }^{14}$ Random examination revealed that the accuracy rate in the remaining sample was more than $99.5 \%$. Less than $0.5 \%$ of the files required manual correction.

${ }^{15}$ See Appendix B for details related to content analytics and dictionary construction, Appendix C for a description of the feature selection algorithm, and Appendix D for the list of dictionary words and phrases.

${ }^{16}$ Outcome variable for a proxy $\mathrm{Y}$ is computed as $\log (1+\mathrm{Y})$. The coefficient on any independent variable $\mathrm{X}$ used in the estimation can be interpreted as the percentage change in $\mathrm{Y}$ for a unit change in $\mathrm{X}$.
} 
Moreover, this suggests that bond issuers rely on multiple disclosure channels, such as management guidance and numerical information embedded in MD\&A, when rating agencies suffer a reputation shock.

From the above results, it is not clear whether such quantitative information is provided by firms with the specific intent of informing creditors about the credit quality of the firm. Results from estimating equation (1) using LOGPROPCRD as the outcome variable provide some insights on this issue (see columns (2) and (4) of Table 12). The coefficient on POST $\mathrm{x}$ TREAT is positive (0.025) and significant at the $1 \%$ level for the SOX sample. In other words, treatment firms increased the proportion of words and phrases in the MD\&A that convey credit risk related information more than control firms did when credit rating agencies lost their reputation. Similarly, the coefficient on POST x TREAT is negative (-0.013), as expected, and significant at the $1 \%$ level for the CRARA sample. These findings provide evidence that managers alter MD\&A content specifically to inform investors about credit risk when rating agencies are affected by reputation shocks.

\subsubsection{Qualitative Information in Management Forecasts}

Next, I proceed to evaluate whether changes in the issuance of management guidance by treatment firms subsequent to reputation shocks are a result of firms' intent to inform creditors about credit risk. I achieve this by analyzing the qualitative statements made by managers when issuing management guidance and examining the extent to which they contain information about credit risk. Effectively, this amounts to an examination of the context in which managers issue guidance and provides insights into the specific reason for issuing guidance. Typically, management guidance is issued via press releases or earnings conference calls. 
In order to obtain qualitative statements corresponding to guidance issuance, I download detailed reports on guidance summary from Thomson ONE database that correspond to the observations in my sample. Since Thomson ONE began issuing guidance reports starting end of FY 2004, my final sample consists of reports corresponding to 1066 firms (11,141 firm quarters) in the CRARA sample. ${ }^{17}$ These guidance reports include qualitative excerpts from press releases and earnings conference call transcripts that capture the specific textual context in which firms issued forecasts along with the issue date and time. I extract the textual information for each firmquarter, save them in separate text files, and perform the same analysis as outlined earlier.

I construct a new proxy for disclosure, PROPCRDFCAST\%, computed as the proportion of words and phrases in the text surrounding guidance issuance that represent credit risk related information. Descriptive statistics in Table 1 Panel B show that, on average, about 3.5\% (3.2\%) of the words used by treatment firms (control firms) when issuing forecasts are credit risk related. The results obtained from estimating equation (1) using logarithm of PROPCRDFCAST\% as the outcome variable are documented in Table 13. The coefficient on the variable of interest, POST $\mathrm{x}$ TREAT, is negative (-0.030) as expected, and statistically significant at the 5\% level. In other words, when the reputation of rating agencies improved, treatment firms not only reduce issuance of management guidance compared to control firms, but also discuss less about credit risk when issuing guidance compared to control firms. This provides support for the argument that firms alter guidance issuance to inform investors about credit risk when rating agencies lose or gain reputation.

\footnotetext{
${ }^{17}$ The time period restriction precludes me from obtaining guidance reports for the SOX sample that spans FY 20012003.
} 


\section{Conclusion}

The primary objective of this study is to explore whether, when, and to what extent reputation of rating agencies affects the discretionary disclosure of corporate bond issuers. CRAs have been facing increased investor criticism and regulatory scrutiny over the last decade, particularly after their failure to predict high profile bankruptcies such as Enron and WorldCom in a timely manner. The impact of such externalities caused by information intermediaries on the disclosure practices of firms is ambiguous and depends crucially on how managers perceive the role played by the specific intermediary in informing capital markets.

Regulatory response to address concerns about the role of CRAs involved the passage of the SOX act in 2002 that required the SEC to investigate the role and function of credit rating agencies, leading to a lengthy regulatory review process that ultimately resulted in the passage of the US Credit Rating Agency Reform Act (CRARA) in 2006. Using such regulatory actions as exogenous shocks to the reputation of CRAs, my study finds evidence consistent with increased investor demand for disclosure from corporate bond issuers when the reputation of rating agencies is at stake. I also find some evidence that the increase in disclosure is more pronounced for firms with "investment grade" rating compared to those with "speculative grade" as good (credit) quality firms have an incentive to distinguish themselves from poor quality firms. These findings are robust to controlling for previously known determinants of disclosure and contemporaneous changes in credit ratings. I use multiple disclosure measures based on management forecasts and MD\&A content to validate my findings. Additionally, using a custom dictionary for measuring credit risk related information in qualitative disclosures, I find that managers increase the issuance of guidance specifically with the intent of informing creditors about the creditworthiness of the firms when CRAs suffer a loss in reputation. 
This study contributes to the accounting and finance literatures in several ways. I provide evidence on how the quality of an information intermediary influences a firm's disclosure decisions. Practitioners and researchers alike find it hard to identify whether stock and bond markets react to rating changes as a result of incremental information provided by the ratings or simply as a response to the changed regulatory status of the bond. I adopt a disclosure perspective to help separate out the two effects and the results support the notion that corporate credit ratings provide incremental information because managers find it in their best interests to increase discretionary disclosure to inform investors when the rating agencies suffer a reputation loss. The findings provide empirical support that regulatory action to monitor information intermediaries (i.e. monitor the monitors) do benefit firms by lowering disclosure costs. Further, my study adds to the current literature on the determinants of risk disclosures. By using qualitative disclosures to support quantitative information, managers are able to credibly signal their firms' credit quality to investors.

In the aftermath of the financial crisis of 2008, policy makers and financial regulators have resorted to numerous measures aimed at reducing investors' reliance on credit ratings. The evidence in this paper suggests that it is premature to dismiss the usefulness of credit ratings. Recent financial reforms such as the Dodd-Frank Act of 2010 have revoked special privileges given to CRAs (such as Reg FD exemption and immunity from lawsuits), removed regulatory references to credit ratings, reduced entry barriers to the rating industry, and enhanced CRA oversight and monitoring. Many of these recent reforms were motivated by the alleged lack of due diligence on part of the CRAs in rating structured finance products during the financial crises and are intended to benefit the financial markets in the long run. However, it is also possible that regulatory reforms may have gone too far and some of the actions, such as removal of the Reg FD exemption, may negatively impact the information content of corporate credit ratings. A recent 
study by Dimitrov et al. (2015) argues that increase in legal and regulatory costs subsequent to the Dodd-Frank act adversely impacted the quality of corporate credit ratings. Nevertheless, media reports attest that the big rating firms are stronger than ever, investors continue to rely on ratings, and rating industry profits are continuing to soar (WSJ, 2016). Whether the reforms have changed the corporate disclosure landscape in a manner that is detrimental to overall social welfare is an important question. Future research can perhaps shed more light on unintended consequences of recent reforms on the informational value provided by corporate ratings and the disclosure costs borne by bond issuers. 


\section{Appendix A - Control Variables}

\section{Description of Control Variables}

\begin{tabular}{|c|c|}
\hline Variable & Description \\
\hline LOGASSETS & $\begin{array}{l}\text { Natural logarithm of the book value of total assets. This variable controls for } \\
\text { size.[Compustat: } \log (a t q)]\end{array}$ \\
\hline ВТОМ & $\begin{array}{l}\text { Ratio of the book value of total assets to the sum of firm's market capitalization } \\
\text { and book value of liabilities. This variable controls for firm's growth } \\
\text { opportunities. [Compustat: atq / (ltq }+ \text { prccq*cshoq)] }\end{array}$ \\
\hline FIRMRET & $\begin{array}{l}\text { Stock return during the quarter. This variable controls for firm performance. } \\
\text { [CRSP] }\end{array}$ \\
\hline RETVOL & $\begin{array}{l}\text { Standard deviation of daily stock returns during the quarter. This variable } \\
\text { controls for uncertainty regarding future performance.[CRSP] }\end{array}$ \\
\hline NUMANAL & $\begin{array}{l}\text { Number of analysts following the firm. This variable controls for shareholder } \\
\text { demand for disclosure.[IBES: number of one-quarter ahead analyst forecasts] }\end{array}$ \\
\hline BADNEWS & $\begin{array}{l}\text { Indicator variable set to one if firm experienced negative stock return during } \\
\text { the quarter and zero otherwise. This variable controls for bad news that } \\
\text { managers may disclose early through forecasts to avoid litigation. [CRSP] }\end{array}$ \\
\hline SURPRISE & $\begin{array}{l}\text { Absolute value of the difference between actual earnings per share and most } \\
\text { recent one-quarter ahead median analyst forecast, scaled by price per share at } \\
\text { the end of the quarter. This variable controls for manager's propensity to issue } \\
\text { forecasts when actual results are likely to differ from market } \\
\text { expectations.[IBES] }\end{array}$ \\
\hline DISPERSION & $\begin{array}{l}\text { Standard deviation of analyst's one-quarter-ahead forecasts. This variable } \\
\text { controls for market uncertainty regarding firm performance for the } \\
\text { quarter.[IBES] }\end{array}$ \\
\hline BLOCK & $\begin{array}{l}\text { Indicator variable for the presence of a blockholder, which is defined as any } \\
\text { institutional investor that owns greater than 5\% of the firm's outstanding } \\
\text { equity. This variable controls for blockholder demand for disclosure [Thomson } \\
\text { Financial } 13 F \text { institutional holdings database] }\end{array}$ \\
\hline WCTA & $\begin{array}{l}\text { Liquidity Ratio. Working Capital (current assets - current liabilities) divided } \\
\text { by Total Assets. [Compustat: }(a c t q-l c t q) / \text { atq ]. }\end{array}$ \\
\hline LEVTA & Leverage ratio. Total Liabilities divided by Total Assets. [Compustat: ltq/atq] \\
\hline EBITTA & $\begin{array}{l}\text { Productivity Ratio. Earnings Before Interest and Taxes divided by Total Assets. } \\
\text { [Compustat: oiadpq/atq] }\end{array}$ \\
\hline MVETL & $\begin{array}{l}\text { Solvency Ratio. Market Value of Equity divided by Total Liabilities. } \\
\text { [Compustat: }(\text { cshoq*prccq)/ltq] }\end{array}$ \\
\hline SALETA & Capital Turnover Ratio. Sales divided by Total Assets. [Compustat: saleq/atq] \\
\hline
\end{tabular}




\section{Appendix B - Content Analytics}

\section{Custom Dictionary for Content Analytics}

Content Analytics refers to a broad range of techniques adopted for analyzing semistructured and unstructured data to extract meanings, patterns, and hidden structures. Corporate disclosures consist of a large amount of unstructured textual information in addition to quantitative information. ${ }^{1}$ With the advent of sophisticated computing machinery, a wide variety of methods and algorithms are available for processing textual content and converting it into numerical variables that can be easily integrated into traditional statistical analysis for extracting meaningful information and inference.

Content analysis using automated techniques and computer programs typically comprises a rule-based dictionary approach or a statistical learning approach ( $\mathrm{Li}, 2010 \mathrm{a})$. The dictionary approach uses a mapping algorithm that processes text and computes the frequency of occurrence of a given set of words and/or phrases (i.e. dictionary) based on pre-defined rules. A statistical learning approach, on the other hand, relies on training data and/or statistical techniques to conduct content analysis.

Dictionary-based techniques for analyzing linguistic content in corporate disclosures are becoming increasingly common in finance and accounting literature (Tetlock et al., 2008; Kothari et al., 2009; Merkley, 2014). Typically, researchers rely on a pre-existing dictionary (Pennebaker and Tausczik, 2010; Loughran and McDonald, 2011) or a custom dictionary tailored to the specific disclosure setting being examined. Commercial software such as the General Inquirer

\footnotetext{
${ }^{1}$ As outlined in Li (2010a), unstructured information refers to information that either does not have a predefined data model and/or does not fit well into relational database tables. Textual information is categorized as unstructured even though it may be physically organized in the form of paragraphs, chapters, and documents.
} 
(published by Harvard psychologist Philip J. Stone) and Linguistic Inquiry and Word Count (published by University of Texas psychologist James W. Pennebaker) are often used in dictionary-based content analysis. Since pre-existing dictionaries suitable for analyzing a given business setting may not be readily available, Li (2010a) advocates using tailored dictionaries or relying on other statistical learning approaches for performing effective content analysis. Accordingly, recent research papers seem to rely more on custom dictionaries (Campbell et al., 2014; Merkley, 2014) or on more sophisticated statistical learning approaches such as naïvebayesian learning (Li, 2010b; De Franco et al, 2013; Huang et al., 2014) for analyzing linguistic content. In a recent contemporaneous work, Bozanic and Kraft (2015) use linguistic analysis and find that credit analysts use qualitative disclosures in adjusting credit ratings.

Prior research adopts a multitude of approaches for creating custom dictionaries. For example, to measure the emphasis on risk and uncertainty in annual reports, Li (2006) measures the frequency of occurrence of the words \{risk, risks, risky, uncertain, uncertainty, uncertainties \}. Some authors (Kravet and Muslu, 2013; Merkley, 2014) develop a keyword list for constructing a custom dictionary by manually reading specific sections of the annual reports and identifying the most commonly occurring words that capture a specific theme (for example, $R \& D$ related words or risk related words). In a recent paper, Campbell et al. (2014) analyze the "risk factor" section in 10-K filings and identify a list of key risk-related words using a document clustering approach known as Latent Dirichlet Allocation.

In this study, I create a custom dictionary for measuring credit risk related content in textual disclosures. I begin with financial risk related words identified in prior literature (Campbell et al., 2014). Then I augment the dictionary further by performing the following 2 steps: (1) include words and phrases that are most commonly used by firms in providing credit 
risk related information in the "Liquidity and Capital Resources" section of the MD\&A because this portion is likely the most informative to creditors, and (2) include words and phrases that most commonly occur in the MD\&A section of disclosures provided by firms that are tending toward a Chapter 11 or Chapter 7 bankruptcy filing. Firms tending towards bankruptcy filing are likely experiencing severe financial distress and hence facing increased demand for credit risk related information from creditors. Hence, I examine the disclosure content of bankrupt firms and compare it to corresponding disclosures by healthy control firms to identify words that specifically distinguish the former from the latter.

To achieve this, I first identify $10-\mathrm{K}$ filings corresponding to 414 firms that filed for bankruptcy during the period 1995-2012. I extract the MD\&A section and the Liquidity and Capital Resources sub-section from the 10-K filings corresponding to the year before bankruptcy filing. I then create a matched pair sample by identifying 414 healthy control firms that are matched on size, industry, and year. Using this pooled sample of 828 firm-year observations, I extract the most commonly occurring words and phrases in the Liquidity and Capital Resources section using a PERL script. I impose the restriction that the word or phrase should occur in at least $5 \%$ of the sample for it to be included in the dictionary. To select the words and phrases that best distinguish the MD\&A disclosure by bankrupt firms (from corresponding disclosures by control firms), I use the matched-pair sample as a training sample and implement a statistical feature selection algorithm (Manning, Raghavan, and Schutze, 2008) outlined in Appendix C. Appendix D lists the complete set of words and phrases that are included in the custom credit risk dictionary I use in this study. 


\section{Appendix C - Feature Selection}

\section{Feature Selection Algorithm}

Feature selection is the process by which a subset of terms is identified using a training sample for the purpose of text classification. By decreasing the effective vocabulary size and eliminating noise features, feature selection approach increases the efficiency of text classifiers (Manning, Raghavan, and Schutze (2008)).

Given a description $\mathrm{d} \varepsilon \mathbf{X}$ of a document, where $\mathbf{X}$ is the document space and a fixed set of classes/categories $\mathbf{C}=\left\{\mathrm{c}_{1}, \mathrm{c}_{2}, \ldots \ldots \mathrm{c}_{\mathrm{j}}\right\}$, a training set $\mathbf{D}$ is defined as a set of labeled documents $\langle d, c\rangle$, where $\langle d, c\rangle \varepsilon(\mathbf{X} \times \mathbf{C})$. Let $\mathbf{V}$ represent the set of unique terms t that make up the vocabulary of the documents. A basic feature selection algorithm for selecting k-best features using a training set $\mathbf{D}$ computes a utility measure $A(t, c)$ for each term $\mathrm{t} \varepsilon \mathbf{V}$ and selects the k-terms that have the highest values of $A(t, c)$.

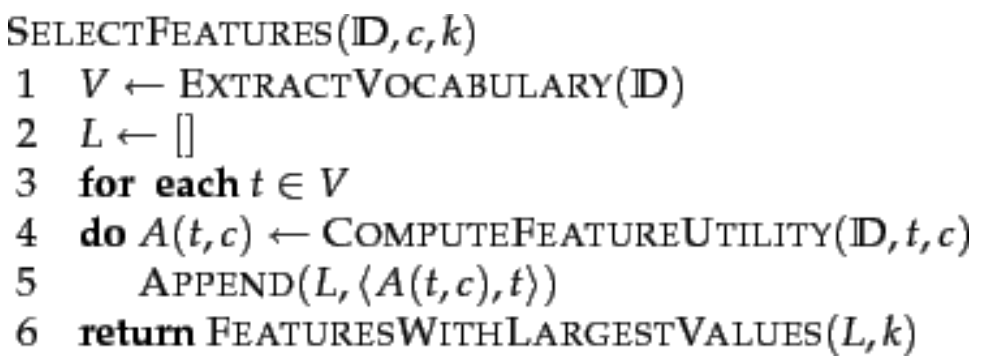

In this study, I use the chi-squared utility measure: $\mathrm{A}(\mathrm{t}, \mathrm{c})=\chi^{2}(\mathrm{t}, \mathrm{c})$. The chi-squared test is used to test the independence of the occurrence of the term and the occurrence of the class. Each term is ranked according to the $\chi^{2}(\mathrm{t}, \mathrm{c})$ measure, and the $\mathrm{k}$ highest ranking terms (that best distinguish one class from the other and statistically significant at the $1 \%$ level) are selected for inclusion in the custom dictionary. 


\section{Appendix D - Credit Risk Dictionary}

Dictionary Words and Phrases 


\section{Dictionary Words}

\begin{tabular}{|c|c|c|c|c|c|c|}
\hline ACQUISITION & CONCERN & EXIT & INDENTURE & MEET & RECOVERABILITY & SENIOR \\
\hline AGREEMENT & CONTINGENCY & EXPENDITURE & INFLATION & MERGER & REDEEM & SETTLEMENT \\
\hline AMEND & CONTRACT & EXPENSE & INSURANCE & MODIFICATION & REDUCTION & SEVERANCE \\
\hline AMENDMENT & COVENANT & FACILITIES & INTEREST & NEGOTIATE & REFINANCE & SEVERE \\
\hline ASSURE & COVERAGE & FAIL & ISSUANCE & NOTE & REINSURANCE & STRATEGY \\
\hline BALANCE & CREDIT & FAILURE & ISSUE & NOTES & RENEGOTIATION & STRONG \\
\hline BANK & CREDITWORTHINESS & FAMILY & LACK & OBLIGATION & REORGANIZATION & STRUCTURE \\
\hline BANKRUPT & DEBT & FILE & LATE & OBLIGATIONS & REORGANIZE & SUBORDINATE \\
\hline BANKRUPTCY & DEEM & FILING & LEASE & OUTSTANDING & REPAY & SUBORDINATED \\
\hline BASE & DEFAULT & FINANCE & LEASEHOLD & OWNERSHIP & REPAYMENT & SUBSTANTIAL \\
\hline BONDHOLDER & DEFICIT & FINANCIAL & LEASES & PAYABLE & RESERVES & SUCCESS \\
\hline BORROW & DELAY & FINANCING & LEASING & PAYMENT & RESTATEMENT & SUFFICIENT \\
\hline BORROWING & DERIVATIVE & FORCE & LEGAL & PENALTY & RESTRICTION & TERM \\
\hline CAPITAL & DIFFICULTY & FUTURE & LENDER & POSTRETIREMENT & RESTRUCTURE & TERMINATE \\
\hline CARRYFORWARD & DILUTION & GOING & LEVERAGE & PREPAYMENT & RESTRUCTURING & TERMINATION \\
\hline CEASE & DISCONTINUE & GROWTH & LIABILITY & PRESSURE & RESULT & UNABLE \\
\hline CLOSE & DISPOSITION & IMPACT & LIQUID & PROCEED & REVOLVING & VALUATION \\
\hline CLOSURE & DISRUPTION & IMPAIRMENT & LIQUIDATION & PROCEEDS & SCHEDULE & VENDOR \\
\hline COLLATERAL & DIVIDENDS & IMPROVEMENTS & LIQUIDITY & PROFITABILITY & SECURE & VOLATILITY \\
\hline COLLECTION & DOUBT & INABILITY & LITIGATION & PROTECTION & SECURED & WARRANT \\
\hline COMMITMENT & DOWNGRADE & INCUR & LOAN & RAISE & SECURITIES & WORTH \\
\hline COMPETITION & ELIMINATION & INDEBTED & LOSS & RATE & SECURITY & WRITE \\
\hline COMPETITOR & EVENT & INDEBTEDNESS & MATURITY & RATING & SEEK & \\
\hline
\end{tabular}




\section{Dictionary Phrases}

\begin{tabular}{|c|c|c|c|c|}
\hline ADDITIONAL CAPITAL & CONTRACTUAL OBLIGATION & FACE VALUE & LOCKED-IN LEASE & WORKFORCE REDUCTION \\
\hline ADDITIONAL FINANCING & COVERAGE RATIO & FINANCIAL CONDITION & LOCKED-IN LEASES & WORKING CAPITAL \\
\hline ADVERSE EFFECT & CREDIT FACILITIES & FINANCIAL COVENANT & LONG-TERM DEBT & WRITE OFF \\
\hline ADVERSE IMPACT & CREDIT FACILITY & FINANCING ARRANGEMENT & MANDATORY CONTRIBUTION & WRITE DOWN \\
\hline ANTI-TAKEOVER PROVISION & CREDIT LINE & FINANCING COSTS & MARKET RISK & WRITE-OFF \\
\hline ANTI-TAKEOVER PROVISIONS & CREDIT RATING & FUNDED STATUS & MATERIAL IMPACT & WRITE-DOWN \\
\hline ASSET SALE & CREDIT RISK & GOING CONCERN & NET LOSS & WRITEOFF \\
\hline BAD DEBT & DEBT BALANCE & INSIDER SALES & NEW FINANCING & \\
\hline BANK BORROWING & DEBT BURDEN & INTEREST PAYMENT & OPERATING LOSS & \\
\hline BANK DEBT & DEBT COVENANT & ISSUANCE COST & OPERATING LOSSES & \\
\hline BORROWING BASE & DEBT DISCOUNT & LEASE COMMITMENT & PENNY STOCK & \\
\hline BORROWING CAPACITY & DEBT EXPENSE & LEASE COMMITMENTS & PRIME RATE & \\
\hline CAPITAL DEFICIENCY & DEBT FINANCING & LEASE OBLIGATION & RATE RISK & \\
\hline CAPITAL EXPENDITURES & DEBT OBLIGATION & LEVERAGED LEASE & RISK FACTOR & \\
\hline CAPITAL LEASE & DEBT REPAYMENT & LEVERAGED LEASES & SELL ASSET & \\
\hline CAPITAL LEASES & DEBT SERVICE & LIKELY TO & SUBJECT TO & \\
\hline CASH NEED & DEFAULT PROVISION & LIMITED TRADING & SUBSTANTIAL DOUBT & \\
\hline CHAPTER 11 & DEFINED BENEFIT & LIQUIDITY NEED & SUFFICIENT CASH & \\
\hline CHAPTER 7 & DISCONTINUE OPERATION & LIQUIDITY POSITION & UNDERFUNDED PENSIONS & \\
\hline CONCENTRATED OWNERSHIP & DISPOSAL ACTIVITY & LOAN AGREEMENT & VARIABLE RATE & \\
\hline
\end{tabular}




\section{Appendix E - Tables and Figures}

Tables and Figures 


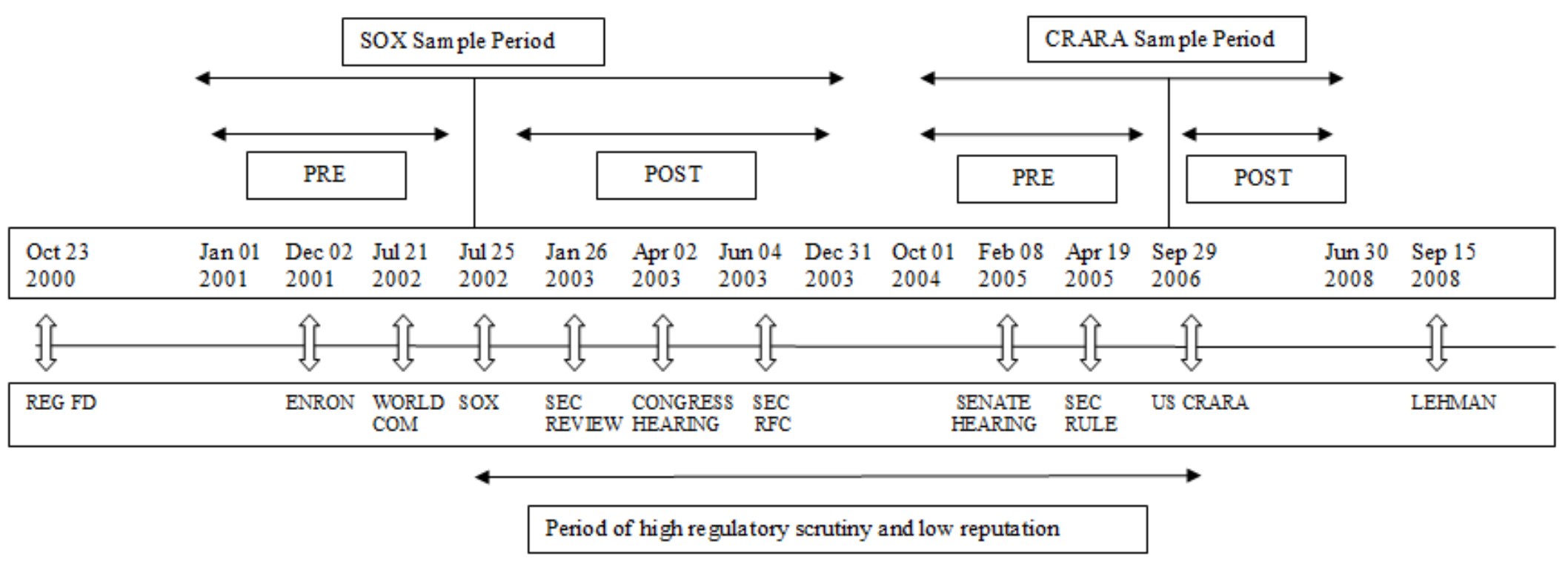

\section{Figure 1}

\section{Timeline of Key Events and Sample Periods}

This figure shows the timeline of key events related to credit rating agencies during the sample period. On Oct 23, 2000, the SEC ratified Regulation FD. Dec 02, 2001 and July 21, 2002 are the dates when Enron and WorldCom, respectively, filed for Chapter 11 bankruptcy. July 25, 2002 is the date when both the Senate and the House passed the Sarbanes-Oxley Act. Section 702(b) of SOX requires the SEC to study the function of rating agencies. On Jan 26, 2003, the SEC issued a first report on the role of rating agencies in the capital markets. On Apr 02, 2003, the Congress started its series of hearings on the credit rating industry. On Jun 04, 2003, an initial SEC concept release invited comments from market participants on rating agencies. On Feb 08, 2005, the Senate Committee on Banking, Housing, and Urban Affairs held a hearing titled "Examining the Role of Credit Rating Agencies in the Capital Markets". On Apr 19, 2005, SEC released a revised rule proposal on the definition of NRSRO. On July 12, 2006, the House approved H.R.2990, the pre-cursor to US CRARA. On Sep 29, 2006, the President signed the "US Credit Rating Agency Reform Act of 2006" into law. On Sep 15, 2008, Lehman Brothers filed for Chapter 11 bankruptcy marking the onset of the financial crisis of 2008. The SOX sample period and the CRARA sample period are centered on the passage of SOX and CRARA acts respectively. The sample periods are further divided into PRE and POST periods. The period between the passage of SOX and CRARA corresponds to a period of high regulatory scrutiny, high investor criticism, and low reputation for the three major nationally recognized issuer-paid credit rating agencies (i.e. Standard \& Poor's, Moody's, Fitch). 


\section{Table 1}

\section{Descriptive Statistics and Correlation Matrix}

Panels A and B provide descriptive statistics for treatment firm-quarter and control firm-quarter observations separately. Both SOX and CRARA sample observations are included. Panels C and D provide the correlation matrices for the SOX and CRARA samples respectively. Spearman correlation is shown above the diagonal and Pearson below. All continuous variables are winsorized at $1 \%$ and $99 \%$. Two-tailed p-values are shown. All variables are described in Appendix A.

\section{Panel A: Descriptive Statistics}

\begin{tabular}{lccc|crr|c}
\hline \multirow{2}{*}{ Variables } & \multicolumn{3}{c|}{$\begin{array}{c}\text { Treatment firm-quarters } \\
\text { (N=17,067) }\end{array}$} & \multicolumn{3}{c|}{$\begin{array}{c}\text { Control firm-quarters } \\
\text { (N=26,491) }\end{array}$} & $\begin{array}{c}\text { P-value of } \\
\text { Diff. in } \\
\text { Means }\end{array}$ \\
\cline { 2 - 6 } & Mean & Median & $\begin{array}{r}\text { Std. } \\
\text { Dev. }\end{array}$ & Mean & Median & Std. Dev. & Means \\
\hline FCAST & 0.357 & 0.000 & 0.479 & 0.253 & 0.000 & 0.435 & {$[<0.01]$} \\
LOGASSETS & 8.299 & 8.161 & 1.309 & 5.684 & 5.723 & 1.386 & {$[<0.01]$} \\
BTOM & 0.674 & 0.677 & 0.237 & 0.558 & 0.520 & 0.290 & {$[<0.01]$} \\
FIRMRET & 0.043 & 0.034 & 0.200 & 0.047 & 0.024 & 0.276 & {$[0.13]$} \\
RETVOL & 0.022 & 0.019 & 0.012 & 0.032 & 0.028 & 0.016 & {$[<0.01]$} \\
NUMANAL & 10.036 & 9.000 & 6.714 & 5.463 & 4.000 & 4.982 & {$[<0.01]$} \\
BADNEWS & 0.408 & 0.000 & 0.491 & 0.451 & 0.000 & 0.498 & {$[<0.01]$} \\
SURPRISE & 0.004 & 0.001 & 0.012 & 0.007 & 0.002 & 0.016 & {$[<0.01]$} \\
DISPERSION & 0.036 & 0.020 & 0.046 & 0.021 & 0.010 & 0.033 & {$[<0.01]$} \\
BLOCK & 0.683 & 1.000 & 0.465 & 0.665 & 1.000 & 0.472 & {$[<0.01]$} \\
WCTA & 0.119 & 0.093 & 0.151 & 0.336 & 0.321 & 0.248 & {$[<0.01]$} \\
LEVTA & 0.625 & 0.617 & 0.180 & 0.393 & 0.363 & 0.231 & {$[<0.01]$} \\
EBITTA & 0.024 & 0.022 & 0.022 & 0.003 & 0.018 & 0.061 & {$[<0.01]$} \\
MVETL & 2.244 & 1.437 & 3.243 & 9.815 & 4.618 & 13.556 & {$[<0.01]$} \\
SALETA & 0.253 & 0.212 & 0.182 & 0.262 & 0.221 & 0.202 & {$[<0.01]$} \\
\hline
\end{tabular}

Panel B: Descriptive Statistics (Alternate Outcome Variables)

\begin{tabular}{lrrrr|rrrr|c}
\hline \multirow{2}{*}{ Variables } & \multicolumn{4}{c|}{ Treatment firm-quarters } & \multicolumn{4}{c|}{ Control firm-quarters } & $\begin{array}{c}\text { P-value } \\
\text { of Diff. } \\
\text { in } \\
\text { in }\end{array}$ \\
\cline { 2 - 9 } & N & Mean & Median & Std. Dev. & N & Mean & Median & Std. Dev. & Means \\
\hline PROPNUM\% & 15214 & 8.937 & 8.742 & 3.154 & 23934 & 7.970 & 7.942 & 3.130 & {$[<0.01]$} \\
PROPCRD\% & 15214 & 5.798 & 5.685 & 1.284 & 23934 & 5.199 & 5.069 & 1.153 & {$[<0.01]$} \\
PROPCRDFCAST\% & 6282 & 3.509 & 3.402 & 1.392 & 4859 & 3.179 & 3.046 & 1.357 & {$[<0.01]$} \\
\hline
\end{tabular}


Panel C: Correlation Matrix for the SOX Sample $(\mathbf{N}=16,214)$ (Spearman correlation is shown above the diagonal and Pearson below)

\begin{tabular}{|c|c|c|c|c|c|c|c|c|c|c|c|c|c|c|c|c|c|}
\hline \multirow{2}{*}{$\begin{array}{l}\text { Variables } \\
\text { FCAST }\end{array}$} & \multirow{2}{*}{$\begin{array}{r}\text { FCAST } \\
1.000\end{array}$} & \multirow{2}{*}{$\begin{array}{r}\text { TREAT } \\
0.134\end{array}$} & \multicolumn{2}{|c|}{ POST LOGASSEIS } & \multirow{2}{*}{$\begin{array}{c}\text { BTOM } \\
-0.051\end{array}$} & \multirow{2}{*}{$\begin{array}{r}\text { FIRMRET } \\
-0.011\end{array}$} & \multirow{2}{*}{$\begin{array}{r}\text { REIVOL } \\
-0.066\end{array}$} & \multirow{2}{*}{$\begin{array}{r}\text { NUMANAL } \\
0.248\end{array}$} & \multirow{2}{*}{$\begin{array}{r}\text { BADNEWS } \\
-0.005\end{array}$} & \multicolumn{2}{|c|}{ SURPRISE DISPERSION } & \multirow{2}{*}{$\begin{array}{r}\text { BLOCK } \\
0.157\end{array}$} & \multirow{2}{*}{$\begin{array}{r}\text { WCTA } \\
-0.020\end{array}$} & \multirow{2}{*}{$\begin{array}{r}\text { LEVTA } \\
0.046\end{array}$} & \multirow{2}{*}{$\begin{array}{r}\text { EBITTA } \\
0.136\end{array}$} & \multirow{2}{*}{$\begin{array}{r}\text { MVEIL } \\
-0.006\end{array}$} & \multirow{2}{*}{$\begin{array}{r}\text { SALETA } \\
0.175\end{array}$} \\
\hline & & & -0.001 & 0.185 & & & & & & -0.199 & -0.014 & & & & & & \\
\hline & & 0.000 & 0.898 & 0.000 & 0.000 & 0.176 & 0.000 & 0.000 & 0.555 & 0.000 & 0.069 & 0.000 & 0.010 & 0.000 & 0.000 & 0.455 & 0.000 \\
\hline \multirow[t]{2}{*}{ TREAT } & 0.134 & 1.000 & 0.005 & 0.737 & 0.193 & -0.029 & -0.366 & 0.409 & -0.014 & -0.118 & 0.288 & 0.013 & -0.455 & 0.554 & 0.120 & -0.483 & -0.031 \\
\hline & 0.000 . & & 0.528 & 0.000 & 0.000 & 0.000 & 0.000 & 0.000 & 0.085 & 0.000 & 0.000 & 0.087 & 0.000 & 0.000 & 0.000 & 0.000 & 0.000 \\
\hline \multirow[t]{2}{*}{ POST } & -0.001 & 0.005 & 1.000 & 0.024 & 0.019 & 0.188 & -0.186 & 0.017 & -0.177 & 0.017 & -0.037 & 0.051 & -0.001 & 0.021 & 0.064 & -0.028 & 0.043 \\
\hline & 0.898 & 0.528 . & & 0.002 & 0.014 & 0.000 & 0.000 & 0.031 & 0.000 & 0.032 & 0.000 & 0.000 & 0.885 & 0.008 & 0.000 & 0.000 & 0.000 \\
\hline \multirow[t]{2}{*}{ LOGASSEIS } & 0.181 & 0.708 & 0.025 & 1.000 & 0.167 & -0.037 & -0.491 & 0.614 & -0.027 & -0.240 & 0.358 & 0.018 & -0.505 & 0.500 & 0.203 & -0.438 & -0.044 \\
\hline & 0.000 & 0.000 & 0.002 & & 0.000 & 0.000 & 0.000 & 0.000 & 0.001 & 0.000 & 0.000 & 0.025 & 0.000 & 0.000 & 0.000 & 0.000 & 0.000 \\
\hline \multirow[t]{2}{*}{ втом } & -0.058 & 0.161 & 0.011 & 0.134 & 1.000 & -0.160 & 0.014 & -0.245 & 0.125 & 0.353 & 0.127 & -0.051 & -0.251 & 0.273 & -0.335 & -0.744 & -0.095 \\
\hline & 0.000 & 0.000 & 0.149 & 0.000 & & 0.000 & 0.077 & 0.000 & 0.000 & 0.000 & 0.000 & 0.000 & 0.000 & 0.000 & 0.000 & 0.000 & 0.000 \\
\hline \multirow[t]{2}{*}{ FIRMRET } & -0.026 & -0.045 & 0.173 & -0.068 & -0.178 & 1.000 & -0.056 & -0.050 & -0.844 & -0.046 & -0.048 & 0.039 & 0.030 & 0.003 & 0.089 & 0.080 & 0.096 \\
\hline & 0.001 & 0.000 & 0.000 & 0.000 & 0.000 & & 0.000 & 0.000 & 0.000 & 0.000 & 0.000 & 0.000 & 0.000 & 0.709 & 0.000 & 0.000 & 0.000 \\
\hline \multirow[t]{2}{*}{ REIVOL } & -0.069 & -0.326 & -0.186 & -0.447 & 0.074 & 0.004 & 1.000 & -0.212 & 0.166 & 0.276 & -0.146 & -0.116 & 0.391 & -0.299 & -0.424 & 0.193 & -0.144 \\
\hline & 0.000 & 0.000 & 0.000 & 0.000 & 0.000 & 0.577 . & & 0.000 & 0.000 & 0.000 & 0.000 & 0.000 & 0.000 & 0.000 & 0.000 & 0.000 & 0.000 \\
\hline \multirow[t]{2}{*}{ NUMANAL } & 0.216 & 0.377 & 0.024 & 0.585 & -0.245 & -0.068 & -0.159 & 1.000 & 0.015 & -0.391 & 0.361 & 0.086 & -0.159 & 0.083 & 0.212 & 0.087 & -0.039 \\
\hline & 0.000 & 0.000 & 0.003 & 0.000 & 0.000 & 0.000 & 0.000 & & 0.061 & 0.000 & 0.000 & 0.000 & 0.000 & 0.000 & 0.000 & 0.000 & 0.000 \\
\hline BADNEWS & -0.005 & -0.014 & -0.177 & -0.025 & 0.135 & -0.709 & 0.150 & 0.018 & 1.000 & 0.067 & 0.021 & -0.049 & 0.013 & -0.028 & -0.116 & -0.047 & -0.094 \\
\hline & 0.555 & 0.085 & 0.000 & 0.002 & 0.000 & 0.000 & 0.000 & 0.025 . & & 0.000 & 0.007 & 0.000 & 0.089 & 0.000 & 0.000 & 0.000 & 0.000 \\
\hline SURPRISE & -0.128 & -0.097 & -0.036 & -0.188 & 0.309 & -0.096 & 0.366 & -0.218 & 0.097 & 1.000 & 0.072 & -0.123 & 0.007 & 0.085 & -0.351 & -0.257 & -0.122 \\
\hline & 0.000 & 0.000 & 0.000 & 0.000 & 0.000 & 0.000 & 0.000 & 0.000 & 0.000 . & & 0.000 & 0.000 & 0.385 & 0.000 & 0.000 & 0.000 & 0.000 \\
\hline DISPERSION & -0.069 & 0.199 & -0.041 & 0.249 & 0.166 & -0.044 & -0.058 & 0.071 & 0.024 & 0.119 & 1.000 & 0.046 & -0.202 & 0.223 & -0.034 & -0.222 & -0.138 \\
\hline & 0.000 & 0.000 & 0.000 & 0.000 & 0.000 & 0.000 & 0.000 & 0.000 & 0.002 & 0.000 . & & 0.000 & 0.000 & 0.000 & 0.000 & 0.000 & 0.000 \\
\hline BLOCK & 0.157 & 0.013 & 0.051 & 0.012 & -0.064 & 0.024 & -0.154 & 0.028 & -0.049 & -0.156 & -0.021 & 1.000 & 0.069 & -0.013 & 0.147 & 0.034 & 0.142 \\
\hline & 0.000 & 0.087 & 0.000 & 0.116 & 0.000 & 0.002 & 0.000 & 0.000 & 0.000 & 0.000 & 0.009 . & & 0.000 & 0.091 & 0.000 & 0.000 & 0.000 \\
\hline WCTA & -0.048 & -0.449 & -0.011 & -0.496 & -0.214 & 0.026 & 0.342 & -0.141 & 0.024 & -0.028 & -0.163 & 0.044 & 1.000 & -0.646 & -0.147 & 0.581 & 0.023 \\
\hline & 0.000 & 0.000 & 0.171 & 0.000 & 0.000 & 0.001 & 0.000 & 0.000 & 0.002 & 0.000 & 0.000 & 0.000 . & & 0.000 & 0.000 & 0.000 & 0.003 \\
\hline LEVTA & 0.044 & 0.525 & 0.026 & 0.440 & 0.192 & 0.006 & -0.230 & 0.031 & -0.028 & 0.112 & 0.193 & -0.018 & -0.637 & 1.000 & 0.070 & -0.809 & 0.122 \\
\hline & 0.000 & 0.000 & 0.001 & 0.000 & 0.000 & 0.421 & 0.000 & 0.000 & 0.000 & 0.000 & 0.000 & 0.023 & 0.000 . & & 0.000 & 0.000 & 0.000 \\
\hline EBITTA & 0.141 & 0.196 & 0.076 & 0.326 & -0.160 & 0.082 & -0.485 & 0.186 & -0.126 & -0.344 & -0.031 & 0.174 & -0.251 & 0.130 & 1.000 & 0.125 & 0.487 \\
\hline & 0.000 & 0.000 & 0.000 & 0.000 & 0.000 & 0.000 & 0.000 & 0.000 & 0.000 & 0.000 & 0.000 & 0.000 & 0.000 & 0.000 . & & 0.000 & 0.000 \\
\hline MVEIL & -0.054 & -0.334 & -0.059 & -0.311 & -0.487 & 0.073 & 0.207 & 0.015 & -0.015 & -0.106 & -0.115 & 0.005 & 0.517 & -0.585 & -0.109 & 1.000 & -0.053 \\
\hline & 0.000 & 0.000 & 0.000 & 0.000 & 0.000 & 0.000 & 0.000 & 0.062 & 0.054 & 0.000 & 0.000 & 0.540 & 0.000 & 0.000 & 0.000 & & 0.000 \\
\hline SALETA & 0.154 & -0.035 & 0.034 & -0.046 & -0.083 & 0.083 & -0.131 & -0.032 & -0.080 & -0.070 & -0.102 & 0.116 & -0.044 & 0.128 & 0.371 & -0.162 & 1.000 \\
\hline & 0.000 & 0.000 & 0.000 & 0.000 & 0.000 & 0.000 & 0.000 & 0.000 & 0.000 & 0.000 & 0.000 & 0.000 & 0.000 & 0.000 & 0.000 & 0.000 & \\
\hline
\end{tabular}




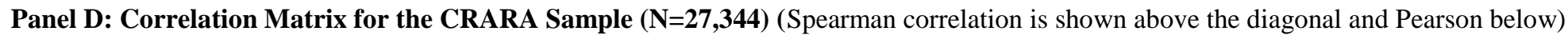

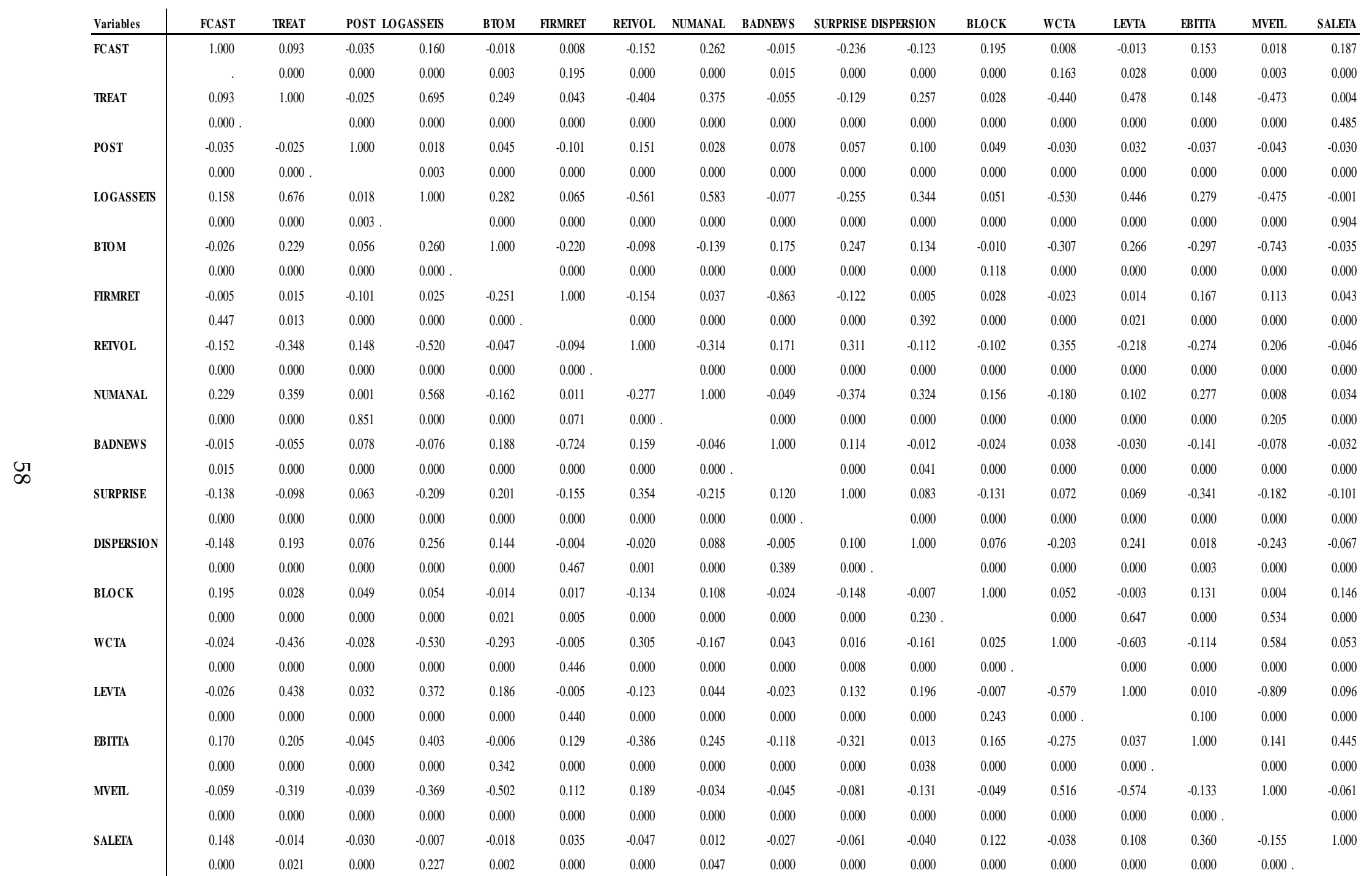




\section{Table 2}

\section{Investor Response to Reputation Shocks}

This table reports the results from estimating regression equation (2) for rating downgrades and upgrades separately for the SOX and CRARA samples. In Panel A, the outcome variable, AAR, measures the absolute abnormal stock return for the bond issuer on the day of rating change. In Panel B, the outcome variable, SAR measures the signed abnormal stock return for the bond issuer on the day of rating change. T-statistics, included in brackets, are computed using robust standard errors. Two-tailed p-values are reported: *** $\mathrm{p}<0.01, * * \mathrm{p}<0.05, * \mathrm{p}<0.10$.

\section{Panel A: Outcome Variable AAR (Absolute Abnormal Return)}

\begin{tabular}{lcccc}
\hline Sample & SOX & SOX & CRARA & CRARA \\
\hline Variable & $\boldsymbol{A A R}$ & $\boldsymbol{A A R}$ & $\boldsymbol{A A R}$ & $\boldsymbol{A A R}$ \\
\hline Rating Change & Downgrade & Upgrade & Downgrade & Upgrade \\
\hline Column & $(\mathbf{1})$ & $(\mathbf{2})$ & $(3)$ & $(\mathbf{4})$ \\
\hline $\boldsymbol{P O S T}$ & $\mathbf{- 0 . 0 1 7 4 * * *}$ & $\mathbf{- 0 . 0 0 9 4 * * *}$ & $\mathbf{0 . 0 1 9 6 * * *}$ & $\mathbf{0 . 0 0 9 4 * *}$ \\
& {$[-4.08]$} & {$[-4.14]$} & {$[2.79]$} & {$[2.23]$} \\
ABS_RAT_CHG & $\mathbf{0 . 0 1 8 6 * * *}$ & -0.0019 & $\mathbf{0 . 0 1 2 8 * * *}$ & 0.0015 \\
& {$[5.01]$} & {$[-1.17]$} & {$[3.25]$} & {$[0.79]$} \\
$\boldsymbol{I G R A D E}$ & -0.0046 & 0.0033 & -0.0019 & -0.0014 \\
& {$[-0.62]$} & {$[0.72]$} & {$[-0.35]$} & {$[-0.73]$} \\
DAYS_CHG & $\mathbf{- 0 . 0 1 7 8 * * *}$ & -0.0008 & $\mathbf{- 0 . 0 1 6 9 * * *}$ & 0.0006 \\
& {$[-6.75]$} & {$[-0.48]$} & {$[-5.36]$} & {$[0.91]$} \\
\hline $\boldsymbol{N}$ & 1887 & 403 & 1453 & 1181 \\
$\boldsymbol{R}$-squared & $9.42 \%$ & $4.85 \%$ & $8.19 \%$ & $2.18 \%$ \\
\hline
\end{tabular}

Panel B: Outcome Variable SAR (Signed Abnormal Return)

\begin{tabular}{lcccc}
\hline Sample & SOX & SOX & CRARA & CRARA \\
\hline Variable & SAR & SAR & SAR & SAR \\
\hline Rating Change & Downgrade & Upgrade & Downgrade & Upgrade \\
\hline Column & $(\mathbf{1})$ & $(2)$ & $(3)$ & $(\mathbf{4})$ \\
\hline POST & $\mathbf{0 . 0 0 7 8 * * *}$ & $\mathbf{- 0 . 0 0 6 1 * * *}$ & $\mathbf{- 0 . 0 1 6 5 * *}$ & $\mathbf{0 . 0 0 2 2} * * *$ \\
& {$[11.30]$} & {$[-7.78]$} & {$[-2.09]$} & {$[4.30]$} \\
ABS_RAT_CHG & $\mathbf{- 0 . 0 1 3 0 * *}$ & -0.0027 & -0.0084 & -0.0024 \\
& {$[-2.20]$} & {$[-1.37]$} & {$[-0.82]$} & {$[-0.99]$} \\
IGRADE & -0.0033 & $\mathbf{0 . 0 0 9 7 * *}$ & $\mathbf{0 . 0 2 0 2} * * *$ & $\mathbf{0 . 0 0 5 6 * *}$ \\
& {$[-0.47]$} & {$[2.57]$} & {$[3.02]$} & {$[2.39]$} \\
DAYS_CHG & $\mathbf{0 . 0 1 3 2 * * *}$ & -0.0012 & $\mathbf{0 . 0 1 5 2} * * *$ & -0.0000 \\
& {$[3.51]$} & {$[-0.32]$} & {$[4.68]$} & {$[-0.05]$} \\
\hline $\boldsymbol{N}$ & 1887 & 403 & 1453 & 1181 \\
$\boldsymbol{R}$-squared & $3.77 \%$ & $2.37 \%$ & $5.66 \%$ & $0.35 \%$ \\
\hline
\end{tabular}




\section{Table 3}

\section{Estimation of Difference-in-Differences (DiD) Model}

This table reports the results from estimating regression equation (1) for the SOX and CRARA samples separately. FCAST is an indicator variable that denotes the incidence of management earnings forecast in the quarter. T-statistics, included in brackets, are computed using robust standard errors clustered at the firm level. Two-tailed p-values are reported: $* * * p<0.01$, $* * \mathrm{p}<0.05, * \mathrm{p}<0.10$. All variables are described in Appendix A.

\begin{tabular}{|c|c|c|c|c|c|c|c|c|}
\hline Sample & & SOX & SOX & SOX & & CRARA & CRARA & CRARA \\
\hline Variable & & FCAST & FCAST & FCAST & & FCAST & FCAST & FCAST \\
\hline Column & Sign & (1) & (2) & (3) & Sign & (4) & (5) & (6) \\
\hline POST $x$ TREAT & + & $\begin{array}{l}\mathbf{0 . 0 4 8}{ }^{* * *} \\
{[3.10]}\end{array}$ & $\begin{array}{c}\mathbf{0 . 0 3 0}^{* *} \\
{[1.97]} \\
\end{array}$ & $\begin{array}{l}\mathbf{0 . 0 4 2} * * * \\
{[2.62]}\end{array}$ & - & $\begin{array}{l}\mathbf{- 0 . 0 5 7} * * * \\
{[-5.03]}\end{array}$ & $\begin{array}{l}\mathbf{- 0 . 0 5 6} * * * \\
{[-4.99]}\end{array}$ & $\begin{array}{l}\mathbf{- 0 . 0 4 6}{ }^{* * *} \\
{[-3.77]}\end{array}$ \\
\hline LOGASSETS & & & $\begin{array}{l}\mathbf{0 . 1 6 7 * * *} \\
{[7.44]}\end{array}$ & $\begin{array}{l}\mathbf{0 . 1 6 5} * * * \\
{[7.27]}\end{array}$ & & & $\begin{array}{c}\mathbf{0 . 0 7 2} * * * \\
{[5.44]}\end{array}$ & $\begin{array}{c}\mathbf{0 . 0 6 6}^{* * * *} \\
{[4.82]}\end{array}$ \\
\hline ВТОМ & & & $\begin{array}{l}\mathbf{- 0 . 1 5 3} * * * \\
{[-4.59]}\end{array}$ & $\begin{array}{l}-\mathbf{0 . 1 5 4} * * * \\
{[-4.68]}\end{array}$ & & & $\begin{array}{c}-\mathbf{0 . 0 9 6} * * * \\
{[-3.47]}\end{array}$ & $\begin{array}{c}\mathbf{- 0 . 1 0 1} * * * \\
{[-3.64]}\end{array}$ \\
\hline FIRMRET & & & $\begin{array}{l}\mathbf{- 0 . 1 1 1} * * * \\
{[-6.78]}\end{array}$ & $\begin{array}{l}\mathbf{- 0 . 1 1 2} * * * \\
{[-6.86]}\end{array}$ & & & $\begin{array}{c}-\mathbf{0 . 0 4 7} * * * \\
{[-3.56]}\end{array}$ & $\begin{array}{c}\mathbf{- 0 . 0 4 3} * * * \\
{[-3.27]}\end{array}$ \\
\hline RETVOL & & & $\begin{array}{l}1.264^{* * * *} \\
{[3.54]}\end{array}$ & $\begin{array}{l}1.258 * * * \\
{[3.52]}\end{array}$ & & & $\begin{array}{r}0.207 \\
{[0.86]}\end{array}$ & $\begin{array}{r}0.236 \\
{[0.98]}\end{array}$ \\
\hline NUMANAL & & & $\begin{array}{l}0.002 \\
{[1.03]}\end{array}$ & $\begin{array}{r}0.003 \\
{[1.26]}\end{array}$ & & & $\begin{array}{l}\mathbf{0 . 0 0 3} * \\
{[1.80]}\end{array}$ & $\begin{array}{c}\mathbf{0 . 0 0 3}^{* *} \\
{[2.39]}\end{array}$ \\
\hline BADNEWS & & & $\begin{array}{l}-\mathbf{0 . 0 2 1} * * \\
{[-2.22]}\end{array}$ & $\begin{array}{l}\mathbf{- 0 . 0 2 2} * * \\
{[-2.34]}\end{array}$ & & & $\begin{array}{l}\mathbf{0 . 0 1 0} * \\
{[1.80]}\end{array}$ & $\begin{array}{c}\mathbf{0 . 0 1 3}^{* *} * \\
{[2.26]}\end{array}$ \\
\hline SURPRISE & & & $\begin{array}{l}-\mathbf{0 . 5 1 5} * * \\
{[-2.01]}\end{array}$ & $\begin{array}{c}-\mathbf{- 0 . 4 9 1} * \\
{[-1.91]}\end{array}$ & & & $\begin{array}{c}-\mathbf{0 . 4 2 4} * * * \\
{[-2.63]}\end{array}$ & $\begin{array}{l}-\mathbf{0 . 4 0 6}{ }^{* *} \\
{[-2.52]}\end{array}$ \\
\hline DISPERSION & & & $\begin{array}{l}\mathbf{- 0 . 2 1 0} * \\
{[-1.66]}\end{array}$ & $\begin{array}{c}-\mathbf{- 0 . 2 3 0} * \\
{[-1.79]}\end{array}$ & & & $\begin{array}{c}-\mathbf{0 . 4 9 7} * * * \\
{[-6.70]}\end{array}$ & $\begin{array}{c}\mathbf{- 0 . 4 9 0} * * * \\
{[-6.69]}\end{array}$ \\
\hline BLOCK & & & $\begin{array}{l}0.030 \\
{[1.50]}\end{array}$ & $\begin{array}{c}0.030 \\
{[1.51]}\end{array}$ & & & $\begin{array}{r}0.014 \\
{[1.23]}\end{array}$ & $\begin{array}{r}0.015 \\
{[1.24]}\end{array}$ \\
\hline Financial Ratios & & $N O$ & $Y E S$ & $Y E S$ & & $N O$ & $Y E S$ & YES \\
\hline Firm FE & & YES & YES & YES & & YES & YES & YES \\
\hline Time FE & & YES & YES & YES & & YES & YES & YES \\
\hline Ind $x$ Year FE & & NO & $\mathrm{NO}$ & YES & & NO & NO & YES \\
\hline$N$ & & 16,214 & 16,214 & 16,214 & & 27,344 & 27,344 & 27,344 \\
\hline$R$-squared & & $44.37 \%$ & $45.32 \%$ & $45.45 \%$ & & $57.14 \%$ & $57.51 \%$ & $57.81 \%$ \\
\hline
\end{tabular}




\section{Table 4}

\section{Partition Based on Rating Changes in Time-series}

This table reports the results from estimating regression equation (1) for the SOX and CRARA samples separately, after partitioning the treatment firms based on rating changes during the sample period . FCAST is an indicator variable that denotes the incidence of management earnings forecast in the quarter. T-statistics, included in brackets, are computed using robust standard errors clustered at the firm level. Two-tailed p-values are reported: $* * * \mathrm{p}<0.01, * * \mathrm{p}<0.05, * \mathrm{p}<0.10$.

\begin{tabular}{|c|c|c|c|c|}
\hline Sample & SOX & SOX & CRARA & CRARA \\
\hline Variable & FCAST & FCAST & FCAST & FCAST \\
\hline Column & (1) & $(2)$ & (3) & (4) \\
\hline \multirow[t]{2}{*}{ POST $x$ RAT_INCR } & $0.059 * *$ & 0.014 & -0.012 & -0.023 \\
\hline & {$[2.10]$} & {$[0.53]$} & {$[-0.77]$} & {$[-1.51]$} \\
\hline \multirow[t]{2}{*}{ POST $x$ RAT_CONS } & $0.059 * * *$ & $0.040 * *$ & $-0.042 * * *$ & $-0.041 * * *$ \\
\hline & {$[3.39]$} & {$[2.35]$} & {$[-3.02]$} & {$[-2.95]$} \\
\hline \multirow[t]{2}{*}{ POST x RAT_DECR } & -0.000 & 0.005 & $-0.102 * * *$ & $-0.089 * * *$ \\
\hline & {$[-0.00]$} & {$[0.21]$} & {$[-5.00]$} & {$[-4.49]$} \\
\hline Control Variables & $N O$ & $Y E S$ & $N O$ & YES \\
\hline Firm FE & $Y E S$ & $Y E S$ & $Y E S$ & $Y E S$ \\
\hline Time FE & $Y E S$ & $Y E S$ & $Y E S$ & $Y E S$ \\
\hline$N$ & 16,214 & 16,214 & 27,344 & 27,344 \\
\hline R-squared & $44.40 \%$ & $45.32 \%$ & $57.18 \%$ & $57.52 \%$ \\
\hline
\end{tabular}




\section{Table 5}

\section{Partition Based on Credit Ratings}

This table reports the results from estimating regression equation (1) for the SOX and CRARA samples separately, after partitioning the treatment firms based on rating grade. FCAST is an indicator variable that denotes the incidence of management earnings forecast in the quarter. T-statistics, included in brackets, are computed using robust standard errors clustered at the firm level. Two-tailed p-values are reported:

$* * * \mathrm{p}<0.01, * * \mathrm{p}<0.05, * \mathrm{p}<0.10$.

\begin{tabular}{|c|c|c|c|c|}
\hline Sample & SOX & SOX & CRARA & CRARA \\
\hline Variable & FCAST & FCAST & FCAST & FCAST \\
\hline Column & (1) & (2) & (3) & (4) \\
\hline \multirow[t]{2}{*}{ POST X INV } & $0.045 * * *$ & & $-0.065^{* * * *}$ & \\
\hline & [2.59] & & {$[-4.86]$} & \\
\hline \multirow[t]{2}{*}{ POST $x$ INV_HIGH } & & 0.059 & & $-0.106 * * *$ \\
\hline & & {$[1.34]$} & & {$[-2.85]$} \\
\hline \multirow[t]{2}{*}{ POST $x$ INV_MED } & & 0.020 & & $-0.041 *$ \\
\hline & & {$[0.78]$} & & {$[-1.92]$} \\
\hline \multirow[t]{2}{*}{ POST $x$ INV_LOW } & & $0.057 * * *$ & & $-0.073^{* * * *}$ \\
\hline & & [2.77] & & {$[-4.66]$} \\
\hline \multirow[t]{2}{*}{ POST $x$ SPEC } & 0.009 & 0.009 & $-0.047 * * *$ & $-0.047 * * *$ \\
\hline & {$[0.45]$} & {$[0.46]$} & {$[-3.23]$} & {$[-3.24]$} \\
\hline Control Variables & YES & YES & YES & $Y E S$ \\
\hline Firm FE & YES & $Y E S$ & YES & YES \\
\hline Time FE & $Y E S$ & $Y E S$ & YES & $Y E S$ \\
\hline$N$ & 16,214 & 16,214 & 27,344 & 27,344 \\
\hline$R$-squared & $45.33 \%$ & $45.34 \%$ & $57.51 \%$ & $57.51 \%$ \\
\hline
\end{tabular}




\section{Table 6}

\section{Partition Based on Egan-Jones Rating}

This table reports the results from estimating regression equation (1) for the SOX and CRARA samples separately, after partitioning the treatment and control firms based on availability of EJR rating. FCAST is an indicator variable that denotes the incidence of management earnings forecast in the quarter. T-statistics, included in brackets, are computed using robust standard errors clustered at the firm level. Two-tailed pvalues are reported: $* * * \mathrm{p}<0.01, * * \mathrm{p}<0.05, * \mathrm{p}<0.10$.

\begin{tabular}{lcc}
\hline Sample & SOX & CRARA \\
\hline Variable & FCAST & FCAST \\
\hline Column & $(1)$ & $(2)$ \\
\hline & & \\
IsSPRated & -0.034 & 0.020 \\
& {$[-0.97]$} & {$[0.79]$} \\
POST $\boldsymbol{x}$ IsSPRated & $\mathbf{0 . 0 4 3 ^ { * * * }}$ & $\mathbf{- 0 . 0 3 7 ^ { * * }}$ \\
& {$[2.22]$} & {$[-2.55]$} \\
IsEJRRated & 0.043 & 0.007 \\
& {$[1.27]$} & {$[0.24]$} \\
POST $\boldsymbol{x}$ IsEJRRated & 0.000 & -0.021 \\
& {$[0.02]$} & {$[-1.32]$} \\
& & \\
\hline Control Variables & $Y E S$ & $Y E S$ \\
Firm FE & $Y E S$ & $Y E S$ \\
Time FE & $Y E S$ & $Y E S$ \\
$\boldsymbol{N}$ & 16,214 & 27,344 \\
$\boldsymbol{R}$-squared & $45.45 \%$ & $57.81 \%$ \\
\hline
\end{tabular}




\section{Table 7}

\section{Partition Based on R\&D Expenses}

This table reports the results from estimating regression equation (1) for the SOX and CRARA samples separately, after partitioning the treatment firms based on R\&D expenses incurred during the fiscal year . FCAST is an indicator variable that denotes the incidence of management earnings forecast in the quarter. T-statistics, included in brackets, are computed using robust standard errors clustered at the firm level. Two-tailed $\mathrm{p}$-values are reported: $* * * \mathrm{p}<0.01, * * \mathrm{p}<0.05, * \mathrm{p}<0.10$.

\begin{tabular}{|c|c|c|c|c|}
\hline Sample & SOX & SOX & CRARA & CRARA \\
\hline Variable & FCAST & FCAST & FCAST & FCAST \\
\hline Column & (1) & (2) & (3) & (4) \\
\hline POST $x$ TREAT_RD & $\begin{array}{l}\mathbf{0 . 0 4 4} * * \\
{[2.11]}\end{array}$ & $\begin{array}{l}\mathbf{0 . 0 4 8}^{* * *} \\
{[2.20]}\end{array}$ & $\begin{array}{l}-\mathbf{- 0 . 0 7 8}^{* * * *} \\
{[-4.44]}\end{array}$ & $\begin{array}{l}\mathbf{- 0 . 0 8 3} * * * * \\
{[-4.39]}\end{array}$ \\
\hline POST $x$ TREAT_NRD & $\begin{array}{r}0.020 \\
{[1.17]} \\
\end{array}$ & $\begin{array}{l}\mathbf{0 . 0 3 8}^{* * *} \\
{[1.96]}\end{array}$ & $\begin{array}{l}-\mathbf{- 0 . 0 4 3} * * * \\
{[-3.59]}\end{array}$ & $\begin{array}{r}-0.019 \\
{[-1.48]}\end{array}$ \\
\hline Control Variables & YES & YES & YES & YES \\
\hline Firm FE & YES & YES & YES & YES \\
\hline Time FE & YES & YES & YES & YES \\
\hline Ind $x$ Year FE & $N O$ & YES & $N O$ & YES \\
\hline$N$ & 16,214 & 16,214 & 27,344 & 27,344 \\
\hline$R$-squared & $45.32 \%$ & $45.45 \%$ & $57.52 \%$ & $57.85 \%$ \\
\hline
\end{tabular}




\section{Table 8}

\section{Partition Based on Immediate Financing Needs}

This table reports the results from estimating regression equation (1) for the SOX and CRARA samples separately, after partitioning the treatment firms based on need for financing. FCAST is an indicator variable that denotes the incidence of management earnings forecast in the quarter. T-statistics, included in brackets, are computed using robust standard errors clustered at the firm level. Two-tailed p-values are reported: $* * * \mathrm{p}<0.01, * * \mathrm{p}<0.05, * \mathrm{p}<0.10$.

\begin{tabular}{lcc}
\hline Sample & SOX & CRARA \\
\hline Variable & FCAST & FCAST \\
\hline Column & $(1)$ & $(2)$ \\
\hline POST $\boldsymbol{x}$ TREAT_HI_FIN & $\mathbf{0 . 0 6 1 * * *}$ & $\mathbf{- 0 . 0 4 7 * * *}$ \\
& {$[3.38]$} & {$[-3.41]$} \\
POST $\boldsymbol{x}$ TREAT_LO_FIN & 0.026 & $\mathbf{- 0 . 0 4 5 * * *}$ \\
& {$[1.36]$} & {$[-3.25]$} \\
\hline & & \\
\hline Control Variables & $Y E S$ & $Y E S$ \\
Firm FE & $Y E S$ & $Y E S$ \\
Time FE & $Y E S$ & $Y E S$ \\
N & 16,214 & 27,344 \\
R-squared & $45.47 \%$ & $57.81 \%$ \\
\hline
\end{tabular}




\section{Table 9}

\section{Timing of Changes in Disclosure}

This table reports the results from estimating regression equation (1) for the SOX and CRARA samples separately, after adding indicator variables to detect parallel trends in the pre-treatment period and persistence of effects in the post-treatment period. FCAST is an indicator variable that denotes the incidence of management earnings forecast in the quarter. T-statistics, included in brackets, are computed using robust standard errors clustered at the firm level. Two-tailed p-values are reported:

$* * * \mathrm{p}<0.01, * * \mathrm{p}<0.05, * \mathrm{p}<0.10$.

\begin{tabular}{|c|c|c|c|c|}
\hline Sample & SOX & SOX & CRARA & CRARA \\
\hline Variable & FCAST & FCAST & FCAST & FCAST \\
\hline Column & (1) & (2) & (3) & (4) \\
\hline \multirow[t]{2}{*}{ BEFORE (-2) $x$ TREAT } & -0.001 & & -0.009 & \\
\hline & {$[-0.07]$} & & {$[-0.56]$} & \\
\hline \multirow[t]{2}{*}{ BEFORE (-1) $x$ TREAT } & 0.023 & & 0.005 & \\
\hline & {$[1.05]$} & & {$[0.50]$} & \\
\hline \multirow[t]{2}{*}{ POST $x$ TREAT } & $0.034 * *$ & & $-0.055 * * *$ & \\
\hline & [1.99] & & {$[-3.98]$} & \\
\hline \multirow[t]{2}{*}{$\operatorname{AFTER}(+1) x \operatorname{TREAT}$} & & $0.054 * * *$ & & $-0.026 * *$ \\
\hline & & {$[3.97]$} & & {$[-2.04]$} \\
\hline \multirow[t]{2}{*}{$\operatorname{AFTER}(+2) x \operatorname{TREAT}$} & & $0.031 *$ & & $-0.072 * * *$ \\
\hline & & {$[1.78]$} & & {$[-4.94]$} \\
\hline \multirow[t]{2}{*}{$\operatorname{AFTER}(+3) \times \operatorname{TREAT}$} & & $0.044 * * *$ & & $-0.042 * * *$ \\
\hline & & {$[2.76]$} & & {$[-2.85]$} \\
\hline Control Variables & $Y E S$ & $Y E S$ & $Y E S$ & $Y E S$ \\
\hline Firm FE & $Y E S$ & $Y E S$ & $Y E S$ & $Y E S$ \\
\hline Time FE & $Y E S$ & $Y E S$ & $Y E S$ & $Y E S$ \\
\hline$N$ & 16,214 & 16,214 & 27,344 & 27,344 \\
\hline R-squared & $45.32 \%$ & $45.46 \%$ & $57.50 \%$ & $57.82 \%$ \\
\hline
\end{tabular}




\section{Table 10}

\section{Nearest Neighbor Matching and Entropy Balancing}

This table reports the results from estimating regression equation (1) for the SOX and CRARA samples separately where the treatment and control firms have been matched using nearest-neighbor (NN) and entropy balancing (EB) techniques. FCAST is an indicator variable that denotes the incidence of management earnings forecast in the quarter. T-statistics, included in brackets, are computed using robust standard errors clustered at the firm level. Two-tailed $\mathrm{p}$-values are reported: $* * * p<0.01, * * p<0.05, * \mathrm{p}$ $<0.10$. All variables are described in Appendix A.

\section{Panel A: Estimation Results}

\begin{tabular}{lcc|cc}
\hline Sample & SOX & SOX & CRARA & CRARA \\
\hline Variable & FCAST & FCAST & FCAST & FCAST \\
\hline Column & $(1)$ & $(2)$ & $(3)$ & $(4)$ \\
\hline \multirow{2}{*}{ POST $\boldsymbol{x}$ TREAT } & $\mathbf{0 . 0 6 4 *}$ & $\mathbf{0 . 0 2 5 * *}$ & $\mathbf{- 0 . 0 3 6 *}$ & $\mathbf{- 0 . 0 3 2 * * *}^{*}$ \\
& {$[1.87]$} & {$[2.00]$} & {$[-1.68]$} & {$[-2.82]$} \\
\hline & & & & \\
\hline Controls & $Y E S$ & $Y E S$ & $Y E S$ & $Y E S$ \\
Firm FE & $Y E S$ & $Y E S$ & $Y E S$ & $Y E S$ \\
Time FE & $Y E S$ & $Y E S$ & $Y E S$ & $Y E S$ \\
Matching & NN & EB & NN & EB \\
$\boldsymbol{N}$ & 4,611 & 16,214 & 9,135 & 27,344 \\
$\boldsymbol{R}$-squared & $45.49 \%$ & $46.23 \%$ & $58.51 \%$ & $53.00 \%$ \\
\hline
\end{tabular}

Panel B: Descriptive Statistics (Entropy Balancing)

\begin{tabular}{|c|c|c|c|c|c|c|c|c|}
\hline & \multicolumn{4}{|c|}{$\operatorname{SOX}(N=16214)$} & \multicolumn{4}{|c|}{ CRARA (N=27344) } \\
\hline & \multicolumn{2}{|c|}{ Treatment } & \multicolumn{2}{|c|}{ Control } & \multicolumn{2}{|c|}{ Treatment } & \multicolumn{2}{|c|}{ Control } \\
\hline & Mean & Variance & Mean & Variance & Mean & Variance & Mean & Variance \\
\hline LOGASSETS & 8.172 & 1.686 & 8.172 & 1.686 & 8.383 & 1.714 & 8.383 & 1.715 \\
\hline ВТОМ & 0.711 & 0.063 & 0.711 & 0.063 & 0.650 & 0.050 & 0.650 & 0.050 \\
\hline FIRMRET & 0.063 & 0.056 & 0.063 & 0.056 & 0.030 & 0.029 & 0.030 & 0.029 \\
\hline RETVOL & 0.027 & 0.000 & 0.027 & 0.000 & 0.020 & 0.000 & 0.020 & 0.000 \\
\hline NUMANAL & 9.700 & 46.020 & 9.700 & 46.020 & 10.260 & 44.340 & 10.260 & 44.350 \\
\hline BADNEWS & 0.381 & 0.236 & 0.381 & 0.236 & 0.425 & 0.245 & 0.425 & 0.244 \\
\hline SURPRISE & 0.004 & 0.000 & 0.004 & 0.000 & 0.004 & 0.000 & 0.004 & 0.000 \\
\hline DISPERSION & 0.030 & 0.002 & 0.030 & 0.002 & 0.040 & 0.002 & 0.040 & 0.002 \\
\hline BLOCK & 0.624 & 0.235 & 0.624 & 0.235 & 0.722 & 0.201 & 0.722 & 0.201 \\
\hline
\end{tabular}




\section{Table 11}

\section{Confounding Effects due to AA Clients}

This table reports the results from estimating regression equation (1) for the SOX sample after removing firms that were audited by Arthur Andersen (AA) during the one-year and two-year period preceding the firm-quarter. FCAST is an indicator variable that denotes the incidence of management earnings forecast in the quarter. T-statistics, included in brackets, are computed using robust standard errors clustered at the firm level. Two-tailed $\mathrm{p}$-values are reported: $* * * \mathrm{p}<0.01, * * \mathrm{p}<0.05, * \mathrm{p}<0.10$. All variables are described in Appendix A.

\begin{tabular}{lcc}
\hline Sample & SOX & SOX \\
\hline Variable & FCAST & FCAST \\
\hline Column & $(1)$ & $(2)$ \\
\hline & & \\
POST $\boldsymbol{x}$ TREAT & $\mathbf{0 . 0 3 9 * *}$ & $\mathbf{0 . 0 3 6 * *}$ \\
& {$[2.35]$} & {$[1.99]$} \\
\hline & & \\
& & \\
\hline Controls & $Y E S$ & $Y E S$ \\
Firm FE & $Y E S$ & $Y E S$ \\
Time FE & $Y E S$ & $Y E S$ \\
Remove AA Clients & $1-\mathrm{year}$ & 2 -year \\
N & 15,138 & 14,144 \\
R-squared & $45.91 \%$ & $46.23 \%$ \\
\hline
\end{tabular}




\section{Table 12}

\section{Estimation of DiD Model for MD\&A Outcome Variables}

This table reports the results from estimating regression equation (1) for the SOX and CRARA samples separately, using the MD\&A outcome variables. The outcome variable, LOGPROPNUM, measures the logarithm of the percentage of numbers in the MD\&A. The outcome variable, LOGPROPCRD, measures the logarithm of the percentage of credit risk related words in the MD\&A. T-statistics, included in brackets, are computed using robust standard errors clustered at the firm level. Two-tailed $\mathrm{p}$-values are reported: $* * *$ $\mathrm{p}<0.01, * * \mathrm{p}<0.05, * \mathrm{p}<0.10$.

\begin{tabular}{|c|c|c|c|c|}
\hline Sample & SOX & SOX & CRARA & CRARA \\
\hline Variable & LOGPROPNUM & LOGPROPCRD & LOGPROPNUM & LOGPROPCRD \\
\hline Column & (1) & (2) & (3) & (4) \\
\hline POST $x$ TREAT & $\begin{array}{l}\mathbf{0 . 0 4 4} * * * * \\
{[3.18]}\end{array}$ & $\begin{array}{l}\mathbf{0 . 0 2 5} * * * * \\
{[4.02]}\end{array}$ & $\begin{array}{l}\mathbf{- 0 . 0 5 6} * * * \\
{[-5.65]}\end{array}$ & $\begin{array}{l}\mathbf{- 0 . 0 1 3} * * * \\
{[-2.92]}\end{array}$ \\
\hline Control Variables & $Y E S$ & $Y E S$ & $Y E S$ & $Y E S$ \\
\hline Firm FE & YES & YES & YES & $Y E S$ \\
\hline Time FE & $Y E S$ & $Y E S$ & $Y E S$ & YES \\
\hline$N$ & 14,732 & 14,732 & 24,416 & 24,416 \\
\hline R-squared & $62.47 \%$ & $69.54 \%$ & $51.80 \%$ & $73.44 \%$ \\
\hline
\end{tabular}




\section{Table 13}

\section{Estimation of DiD Model Using Qualitative Information in Forecasts}

This table reports the results from estimating regression equation (1) for the CRARA sample, using textual analysis of qualitative information in press releases and conference call transcripts surrounding the issuance of management forecasts. The outcome variable, LOGPROPCRDFCAST, measures the logarithm of the percentage of credit risk related words and phrases in the text surrounding management forecasts. Tstatistics, included in brackets, are computed using robust standard errors clustered at the firm level. Twotailed p-values are reported: $* * * \mathrm{p}<0.01, * * \mathrm{p}<0.05, * \mathrm{p}<0.10$.

\begin{tabular}{lc}
\hline Sample & CRARA \\
\hline Variable & LOGPROPCRDFCAST \\
\hline & \\
POST $\boldsymbol{x}$ TREAT & $\mathbf{- 0 . 0 3 0 * *}$ \\
& {$[-2.48]$} \\
\hline & \\
& \\
Control Variables & $Y E S$ \\
Firm FE & $Y E S$ \\
Time FE & $Y E S$ \\
N & 11,141 \\
R-squared & $28.46 \%$ \\
\hline
\end{tabular}




\section{References}

Aboody, D., and B.Lev. 2000. Information Asymmetry, R\&D, and Insider Gains. Journal of Finance 55(6):2747-66

AFP. 2002. Association for Financial Professionals Survey, PRNewswire, http://www.prnewswire.com/news-releases/association-for-financial-professionals-applaudssecurities-and-exchange-commission-report-on-credit-rating-agencies-74055057.html

Altman, E. I. 1968. Financial ratios, discriminant analysis, and the prediction of corporate bankruptcy. Journal of Finance 23: 589-609.

Altman, E.I., and H.A.Rijken. 2004. How rating agencies achieve rating stability. Journal of Banking and Finance 28:2679-2714

Akerlof, G., 1970. The market for lemons: quality uncertainty and the market mechanism. Quarterly Journal of Economics 88:488-500

Balakrishnan, K., M.B.Billings, B.Kelly, and A.Ljungqvist. 2014. Shaping liquidity: On the causal effects of voluntary disclosure. Journal of Finance 69(5):2237-2278

Baik, B., Farber, D., \& Lee, S. 2011. CEO ability and management earnings forecasts. Contemporary Accounting Research 28(5):1645-1668

Beaver, W. H., M. F. McNichols, and J. Rhie. 2005. Have financial statements become less informative? Evidence from the ability of financial ratios to predict bankruptcy. Review of Accounting Studies 10:93-122.

Beaver, W.H., C. Shakespeare, and M.T.Soliman. 2006. Differential properties in the ratings of certified versus non-certified bond-rating agencies. Journal of Accounting and Economics 42:303-34.

Bertrand, M., Duflo, E., and Mullainathan, S. 2004. How much should we trust difference-indifferences estimates? Quarterly Journal of Economics 119:249-275

Beyer, A., Cohen, D.A., Lys, T.Z., and Walther, B.R. 2010. The financial reporting environment: Review of the recent literature. Journal of Accounting and Economics 50:296-343

Bolton, P., Freixas, X., and Shapiro, J. 2012. The Credit Ratings Game. Journal of Finance 67(1):85-111

Bonsall IV, S.B. 2014. The impact of issuer-pay on corporate bond rating properties: Evidence from Moody's and S\&P's initial adoptions. Journal of Accounting and Economics 57:89-109

Boone, J.P., and K.K.Raman. 2001. Off-balance sheet R\&D assets and market liquidity. Journal of Accounting and Public Policy 20:97-128 
Bozanic, Z., and Kraft, P. 2015. Qualitative corporate disclosures and credit analysts' soft rating adjustments. Working Paper.

Cahan, S.F., Chaney, P.K., Jeter, D.C., and W.Zhang. 2013. Damaged auditor reputation and analysts' forecast revision frequency. Auditing: A Journal of Practice and Theory 32(1):33-60

Campbell, J.L., Chen, H., Dhaliwal, D.S., Lu. H., and Steele, L.B. 2014. The information content of mandatory risk factor disclosures in corporate filings. Review of Accounting Studies 19:396455

Chaney, P.K., and K.L.Philipich. 2002. Shredded Reputation: The Cost of Audit Failure. Journal of Accounting Research 40(4):1221-45

Cheng, M. and Neamtiu, M. 2009. An empirical analysis of changes in credit rating properties: Timeliness, accuracy and volatility. Journal of Accounting and Economics 47:108-130

Coffee, J.C. 2011. Ratings Reform: The Good, The Bad, and The Ugly. Harvard Business Law Review 1:231-278

Cole, C.J., and Jones, C.L. 2005. Management Discussion \& Analysis: A review and implications for future research. Journal of Accounting Literature 24:135-174

Cornaggia, J., and Cornaggia, K.J. 2013. Estimating the costs of issuer-paid credit ratings. Review of Financial Studies 26(9):2229-69

De Franco, G., Vasvari, F.P., Vyas, D., and Wittenberg-Moerman, R. 2013. Debt Analysts' Views of Debt-Equity Conflicts of Interest. Chicago Working Paper No.10-13

Demers, E., and Vega,C. 2014. The Impact of Credibility on the Pricing of Managerial Textual Content. Working Paper.

Diamond, D.W. 1984. Financial Intermediation and Delegated Monitoring. Review of Economic Studies 51(3):393-414

Diamond, D.W. 1985. Optimal release of information by firms. Journal of Finance 40(4):10711094

Dichev, I.D., and Piotroski, J.D. 2001. The Long-Run Stock Returns Following Bond Ratings Changes. Journal of Finance 56(1):173-203

Dimitrov, V., Palia, D., and Tang, L. 2015. Impact of the Dodd-Frank act on credit ratings. Journal of Financial Economics 115:505-520

Dye, R.A. 1986. Proprietary and Non-proprietary Disclosures. Journal of Business 59(2):331-366

Foster, G. 1973. Stock Market Reaction to Estimates of Earnings per Share by Company Officials. Journal of Accounting Research 11(1):25-37. 
Frankel, R., M.McNichols, \& G.P.Wilson. 1995. Discretionary disclosure and external financing. The Accounting Review 70 (1):135-150.

Graham, J.R., Harvey, C.R., and Rajgopal, S. 2005. The economic implications of corporate financial reporting. Journal of Accounting and Economics 40:3-73.

Greene, W., 2004. The behavior of the maximum likelihood estimator of limited dependent variable models in the presence of fixed effects. Econometrics Journal 7:98-119.

Hainmueller, J. 2012. Entropy Balancing for Causal Effects: A multivariate reweighting method to produce balanced samples in observational studies. Political Analysis 20(1):25-46

Hand, J., Holthausen, R.W., and Leftwich, R.W. 1992. The effect of bond rating agency announcements on bond and stock prices. Journal of Finance 47(2):733-752

Healy, P.M., and Palepu, K.G. 2001. Information asymmetry, corporate disclosure, and the capital markets: A review of the empirical disclosure literature. Journal of Accounting and Economics 31:405-440

Himmelberg,C.P., and Morgan,D.P. 1995. Is bank lending special? In:Peek,J., Rosengren,J.E. (Eds.), Is Bank Lending Important for the Transmission of Monetary Policy? Conference Series no.39. Federal Reserve Bank, Boston, MA, pp.15-36.

Hirst, D.E., Koonce, L., and Venkataraman, S. 2007. How disaggregation enhanced the credibility of management earnings forecasts. Journal of Accounting Research 45(4):811-837

Holthausen, R.W., and Leftwich, R.W. 1986. The Effect of Bond Rating Changes on Common Stock Prices. Journal of Financial Economics 17:57-89

Huang, A.H., Zang, A.Y., and Zheng, R. 2014. Evidence on the information content of text in analyst reports. The Accounting Review 89(6):2151-2180

Hutton, A. P., G.S. Miller, and D.J.Skinner. 2003. The role of supplementary statements with management earnings forecasts. Journal of Accounting Research 41(5):867-890.

Hull, J., Predescu, M., and White, A. 2004. The relationship between credit default swap spreads, bond yields, and credit rating announcements. Journal of Banking and Finance 28:2789-2811

Jeon, D., and Lovo, S. 2013. Credit rating industry: A helicopter tour of stylized facts and recent theories. International Journal of Industrial Organization 31:643-651

Jorion, P., Liu, Z., and Shi, C. 2005. Informational effects of Regulation FD: evidence from rating agencies. Journal of Financial Economics 76:309-330

Kinney, W.R. 1986. Empirical Accounting Research Design for PhD Students. The Accounting Review 61(2):338-350

Kisgen, D.J., and Strahan, P.E. 2010. Do regulations based on credit ratings affect a firm's cost of capital? Review of Financial Studies 23(12):4324-4347 
Klein, B., and Leffler, K.B. 1981. The role of market forces in assuring contractual performance. Journal of Political Economy 89(4):615-641.

Kliger, D., and O.Sarig. 2000. The information value of bond ratings. Journal of Finance 55(6):2879-2902.

Kothari, S.P., Laguerre, T.E., and Leone, A.J. 2002. Capitalization versus Expensing: Evidence on the uncertainty of future earnings from capital expenditures versus R\&D outlays. Review of Accounting Studies 7:355-382

Kothari, S.P., Li, X., and Short, J.E. 2009. The effect of disclosures by management, analysts, and business press on cost of capital, return volatility, and analyst forecasts: A study using content analysis. The Accounting Review 84(5):1639-1670

Kravet, T., and Muslu, V. 2013. Textual risk disclosures and investors' risk perceptions. Review of Accounting Studies 18:1088-1122

Lambert, R., Leuz, C., and Verrecchia, R.E. 2007. Accounting Information, Disclosure, and the Cost of Capital. Journal of Accounting Research 45(2):385-420

Langohr, H.M. and Langohr, P.T. 2008. The rating agencies and their credit ratings. John Wiley \& Sons Inc., West Sussex.

Leland, H., and Pyle, D. 1977. Information asymmetries, financial structure, and financial intermediaries. Journal of Finance 32:371-387

Leuz, C., and Schrand, C. 2009. Disclosure and the Cost of Capital: Evidence from firms' responses to the Enron shock. Working Paper

Leuz, C., and Verrecchia, R.E 2000. The economic consequences of increased disclosure. Journal of Accounting Research 38:91-124

Li, F. 2006. Do stock market investors understand the risk sentiment of corporate annual reports? Working Paper

Li, F. 2010a. Textual analysis of corporate disclosures: A survey of the literature. Journal of Accounting Literature 29:143-165

Li, F. 2010b. The Information Content of Forward-Looking Statements in Corporate Filings - A Naïve Bayesian Maching Learning Approach. Journal of Accounting Research 48(5):1049-1102

Lo, A.K. 2013. Do declines in bank health affect borrowers' voluntary disclosures? Evidence from international propagation of banking shocks. Journal of Accounting Research 52(2): 541581.

Loughran, T., and McDonald, B. 2011. When is a liability not a liability? Textual analysis, Dictionaries, and 10-Ks. Journal of Finance 66(1):35-65 
Mailath, G.J., and Samuelson, L. 2001. Who wants a good reputation? Review of Economic Studies 68:415-441

Mailath, G.J., and Samuelson, L. 2015. "Reputation in Repeated Games", Handbook of Game Theory, Vol. 4, Elsevier, 2015, Chapter 4, pp. 165-238

Manning, C.D., Raghavan, P., and Schutze, H. 2008. Introduction to Information Retrieval. Cambridge University Press.

Marinovic, I., and Sridhar, S. 2015. Discretionary disclosures using a certifier. Journal of Accounting and Economics 59:25-40

May, A.D. 2010. The impact of bond rating changes on corporate bond prices: New evidence from the over-the-counter market. Journal of Banking and Finance 34:2822-2836

Mayew, W.J., Sethuraman, M., and Venkatachalam,M. 2015. MD\&A Disclosure and the Firm's Ability to Continue as a Going Concern. The Accounting Review 90(4):1621-1651

Merkley, K.J. 2014. Narrative disclosure and earnings performance: Evidence from R\&D disclosures. The Accounting Review 89(2):725-757

Michels, J. 2012. Do unverifiable disclosures matter? Evidence from peer-to-peer lending. The Accounting Review 87(4):1385-1413

Nagar, V., D.Nanda, and P.Wysocki. 2003. Discretionary disclosure and stock-based incentives. Journal of Accounting and Economics 34:283-209.

Nelson, K.K., Price, R.A., and Rountree, B.R. 2008. The market reaction to Arthur Andersen's role in the Enron scandal: Loss of reputation or confounding effects? Journal of Accounting and Economics 46:279-293

Norden, L. and Weber, M. 2004. Informational efficiency of credit default swap and stock markets: The impact of credit rating announcements. Journal of Banking and Finance 28:28132843

Opp, C.C., Opp, M.M., and Harris, M. 2013. Rating agencies in the face of regulation. Journal of Financial Economics 108:46-61

Partnoy, F. 2006. How and why credit rating agencies are not like other gatekeepers? University of San Diego Research Paper No. 07-46

Patell, J.M. 1976. Corporate forecasts of earnings per share and stock price behavior: Empirical tests. Journal of Accounting Research 14(2):246-276

Penman, S. H. (1980). An empirical investigation of the voluntary disclosure of corporate earnings forecasts. Journal of Accounting Research, 18 (1), 132-160.

Pennebaker, J. W., and Y. R. Tausczik. 2010. The psychological meaning of words: LIWC and computerized text analysis methods. Journal of Language and Social Psychology 29: 24-54. 
Pinches, G.E., and Singleton, J.C. 1978. The Adjustment of Stock Prices to Bond Rating Changes. Journal of Finance 33(1):29-44

Pownall,C., Wasley,C., \& Waymire,G. 1993. The stock price effects of alternative types of management earnings forecasts. The Accounting Review 68(4):896-912.

Rogers, J.L., and Stocken, P.C. 2005. Credibility of management forecasts. The Accounting Review 80(4):1233-1260

SEC. 2003a. Report on the role and function of credit rating agencies in the operation of the securities markets. SEC Rep., January 2003, US Securities and Exchange Commission., Washington DC., http://www.sec.gov/news/studies/credratingreport0103.pdf

SEC, 2003b. Interpretation: Commission Guidance Regarding Management's Discussion and Analysis of Financial Condition and Results of Operations. https://www.sec.gov/rules/interp/33$\underline{8350 . h t m}$

Sengupta, P. 1998. Corporate Disclosure Quality and the Cost of Debt. The Accounting Review 73(4):459-474

Shivakumar, L., Urcan, O., Vasvari, F.P., \& Zhang, L. 2011. The debt market relevance of management earnings forecasts: evidence from before and during the credit crisis. Review of Accounting Studies 16:464-486

Shumway, T. 2001. Forecasting bankruptcy more accurately: A simple hazard model. Journal of Business 74: 101-124.

Skinner, D.J. 1994. Why firms voluntarily disclose bad news? Journal of Accounting Research 32(1):38-60

Spence, M. 1973. Job Market Signaling. Quarterly Journal of Economics 87(3):355-374

Stocken, P.C. 2000. Credibility of voluntary disclosure. RAND Journal of Economics 31(2):359374

Strobl, G. and Xia, H. 2012. The issuer-pays rating model and ratings inflation: Evidence from corporate credit ratings. Working Paper.

Tang, T.T. 2009. Information asymmetry and firms' credit market access: Evidence from Moody's credit rating format refinement. Journal of Financial Economics 93(2):325-351

Tetlock, P. C., M. Saar-Tsechansky, and S. Macskassy. 2008. More than words: Quantifying language to measure firms' fundamentals. Journal of Finance 63 (3): 1437-1467.

Tirole, J. 2006. The Theory of Corporate Finance. Princeton University Press.

Trueman,B. 1986. Why do managers voluntarily release earnings forecasts? Journal of Accounting and Economics 8(1):53-72. 
Vashishtha, R. 2014. The role of bank monitoring in borrower's discretionary disclosure: Evidence from covenant violations Journal of Accounting and Economics 57:176-195

Verrecchia, R.E. 1983. Discretionary Disclosure. Journal of Accounting and Economics 5:179194

White, L.J. 2013. Credit Rating Agencies: An Overview. Annual Review of Financial Economics 5:93-122

WSJ, 2016. What crisis? Big ratings firms stronger than ever. [Article by Timothy W. Martin]. http://www.wsj.com/articles/what-crisis-big-ratings-firms-stronger-than-ever-1457655084

Zeibart, D. and Reiter, S. 1992. Bond ratings, bond yields, and financial information. Contemporary Accounting Research. 9(1):252-282 


\section{Biography}

Mani Sethuraman was raised in Chennai, India. He graduated from Birla Institute of Technology and Science (BITS Pilani, India) in 1998 with a bachelor's degree in Electrical Engineering and a master's degree in Physics. He also obtained a master's degree in Electrical and Computer Engineering from the University of Florida at Gainesville in 2001. Prior to pursuing a Ph.D. in business administration, Mani obtained an MBA degree from Duke University and also worked at multinational firms such as Citibank and IBM in various capacities. During his doctoral studies at Duke University, Mani received the prestigious Doctoral Fellowship granted annually to ten top accounting Ph.D. candidates by the Deloitte Foundation. His first faculty position will be as an assistant professor of accounting at the Samuel Curtis Johnson Graduate School of Management, Cornell University. 